\title{
Evidence-based practice guideline for the treatment for diabetes in Japan 2013
}

\author{
Naoko Tajima $\cdot$ Mitsuhiko Noda $\cdot$ Hideki Origasa $\cdot$ Hiroshi Noto $\cdot$ \\ Daisuke Yabe $\cdot$ Yukihiro Fujita $\cdot$ Atsushi Goto $\cdot$ Kei Fujimoto \\ Masaya Sakamoto $\cdot$ Masakazu Haneda
}

Published online: 8 July 2015

(C) The Japan Diabetes Society 2015

Keywords Diabetes · EBM - Guideline - Diagnosis ·

Treatment

\section{Preface}

To promote evidence-based diabetes treatment, the Japan Diabetes Society (JDS) published, in February 2002, our first "Evidence-based Practice Guide for the Treatment of Diabetes in Japan" (J Japan Diab. Soc. 45, Supple 1, 2002). Since then, revised editions have been released every 3 years. Evidence-based medicine is a practice of medicine that attempts to integrate individual physician's clinical

This article is based on a study first reported in the Evidence-based Practice Guideline for the Treatment for Diabetes in Japan 2013 (ISBN978-4-524-26996-9), which was published in Japanese by Nankodo Co., Ltd. (ㄷ The Japan Diabetes Society, 2013).

N. Tajima $(\bowtie) \cdot$ K. Fujimoto $\cdot$ M. Sakamoto Jikei University School of Medicine, Tokyo, Japan e-mail: naokopgh@gmail.com

M. Noda $\cdot$ H. Noto $\cdot$ A. Goto

National Center for Global Health and Medicine, Tokyo, Japan

H. Origasa

University of Toyama School of Medicine, Toyoma, Japan

D. Yabe

Kansai Electric Power Hospital, Osaka, Japan

Y. Fujita $\cdot$ M. Haneda

Asahikawa Medical University, Asahikawa, Japan expertise and the best external research evidence, and apply them to solve individual patient's problems. The physician's clinical expertise decides whether or not the information obtained from the literature can be applied directly to the individual patient. (Sackett, D.L. et al., BMJ 312: 71, 1996).

Based on this policy, this guideline is formulated with several aims: to gather evidence on diabetes treatment both in Japan and overseas, describe it in forms that are easy to understand and use, subject it to evaluation by diabetes specialists, and offer recommendations for diagnosis and treatment. Although the JDS publishes numerous guidelines related to diabetes, it makes sure that all its books including the "Treatment Guide for Diabetes" comply with the recommendations laid out in this guideline. The guideline won plaudits from the Appraisal of Guidelines for Research and Evaluation (AGREE), an external tool for evaluating various guidelines, for its scope and purpose, rigor of development, and clarity of presentation.

The 2013 Edition of the Evidence-based Practice Guideline for the Treatment of Diabetes in Japan consists of 355 pages and 24 chapters. Each chapter has statements, explanations, abstract-tables, and references. The Englishlanguage edition was simplified for publication on our website. It features the entire Statement, plus commentaries that provide explanations of several passages. The tables, figures and references are limited only to those that are necessary. We hope this guideline will be found useful both in Japan and overseas.

- Translated "Statement" of the original Japanese version guideline

- Additional statements abstracted from the "Explanations" of the original Japanese version guideline. 
Table 1 Criteria for Assigning Levels of Evidence to Publications of Interest

\begin{tabular}{|c|c|}
\hline $\begin{array}{l}\text { Level of } \\
\text { evidence }\end{array}$ & Type of evidence \\
\hline \multirow[t]{2}{*}{$1+$} & High-quality ${ }^{\mathrm{a}}$ randomized controlled trials (RCTs) \\
\hline & $\begin{array}{l}\text { Meta-analysis or systematic review of trials with } \\
\text { level } 1+\end{array}$ \\
\hline \multirow[t]{2}{*}{1} & RCTs that fail to meet level $1+$ evidence \\
\hline & $\begin{array}{l}\text { Meta-analysis or systematic review of trials with } \\
\text { level } 1\end{array}$ \\
\hline 2 & $\begin{array}{l}\text { Prospective cohort studies, or meta-analysis or } \\
\text { systematic review of them }\end{array}$ \\
\hline \multirow[t]{5}{*}{3} & Pre-specified sub-analyses of RCTs \\
\hline & Non-randomized controlled trials \\
\hline & Self-controlled (before-after) studies \\
\hline & Retrospective cohort studies \\
\hline & $\begin{array}{l}\text { Case-control studies, or meta-analysis or systematic } \\
\text { review of them }\end{array}$ \\
\hline \multirow[t]{3}{*}{4} & Post-hoc sub-analyses of RCTs \\
\hline & Cross-sectional studies \\
\hline & Case-series \\
\hline
\end{tabular}

$\overline{{ }^{a} \text { A high-quality RCT was defined as an appropriately designed and }}$ conducted trial with a large sample size and a clearly specified randomization scheme, involving double masking and a high rate of follow-up

\section{Methods for developing the "Diabetes Guideline 2013"}

The present guideline consists of important statements intended to assist in clinical practice. They are structured as 24 chapters, with the statement also intended as recommendations. These statements were developed on the basis of published clinical evidence as well as expert consensus.

This guideline offers key recommendations in clinical practice as supported by the scientific evidence available from published studies. Any study of interest was systematically searched using the electronic databases of the MEDLINE and Japanese ICHUSHI (http://www.jamas.or. $\mathrm{jp} /$ ), complemented by the authors' own manual searches. The search strategies used were described in detail in the Japanese original version of the guideline. Any study of interest was critically appraised for their strength by the authors to determine their relevance to any particular statement in the guideline and whether they were worth citing. Each study was assigned a level of evidence using the approach described in Table 1. Criteria for assigning a level of evidence were developed in reference to the previously published guidelines [1-4].

Each statement was assigned a grade of recommendation based on the evidences as well as their methodological strength and applicability to the Japanese population.
Table 2 Grading for recommendation

\begin{tabular}{ll}
\hline A & Strongly recommend \\
B & Recommend \\
C & Insufficient evidence to recommend \\
D & Not recommend \\
\hline
\end{tabular}

Criteria for assigning grades of recommendation were shown in Table 2. Statements were graded as A to D, and the grade of recommendation was determined by the scientific evidence and expert consensus currently available. Statements without original literature were designated as "consensus".

Each chapter involves several statements that were indicated as closed circles. An open circle means a commentary providing with explanations by the authors. Scientific reports supporting a statement were cited as an "References" and additional guidelines or review articles were listed as "Additional reference material".

All authors of the original Japanese version volunteered to assist in the development of the guideline and disclosed all potential conflicts of interest or relationships with manufacturers of any commercial products discussed in the guideline. External peer review of the guideline content was conducted by a panel of third-party experts not involved in the development of the guideline. The guideline will be reviewed in every 3 year, as there will be considerable advances in clinical research and practice in the meantime requiring a re-evaluation of the scientific evidence becoming available.

\section{Guideline for the diagnosis of diabetes mellitus}

\section{Diagnosis of diabetes mellitus}

- The diagnosis of diabetes mellitus should be made as comprehensively as possible, as confirmed by the presence of chronic hyperglycemia, but also by the presence of other factors, such as associated symptoms, clinical laboratory findings, family history of diabetes, and body weight history [1] (grade A; consensus).

\section{Classification of hyperglycemia for diagnosis}

- Based on combined fasting and 2-h post-75 g oral glucose tolerance test (OGTT) glucose values, patients are classified into diabetic, normal, and borderline types (Table 3). Those with casual blood glucose levels $\geq 200 \mathrm{mg} / \mathrm{dL}$ or those with $\mathrm{HbA1c} \geq 6.5 \%$ are also classified as diabetic (grade A; consensus). 
3. Diagnosis of the diabetic type and diabetes (Fig. 1)

- Patients found to be diabetic on $\geq 2$ assessments made on separate days can be diagnosed as having diabetes. Patients must not be diagnosed as having diabetes, based on repeated $\mathrm{HbA1c}$ measurements alone. Patients are diagnosed as having diabetes if they are shown to be diabetic on the basis of both their glucose level and $\mathrm{HbA1c}$ value in a measurement using the same blood sample [1] (grade A; consensus).

- Of those with either of the following criteria, those whose blood glucose level is shown to be diabetic even in a single measurement are diagnosed as having diabetes [1] (grade A; consensus).

(1) presence of typical symptoms of diabetes (e.g., dry mouth, polyposia, polyuria, body weight loss)

(2) presence of diabetic retinopathy

In an epidemiological study aimed to survey the prevalence of diabetes in a population, individuals found to be diabetic and hyperglycemic in a single measurement may be diagnosed as having diabetes [2] (grade A).

\section{Patients with a prior history of "diabetes"}

- Among patients who fail to meet the diagnosis of the diabetic type, those documented as having met the above criteria and having diabetes are handled similarly to those with diabetes [1] (grade A; consensus).

5. Patients not confirmed to be diabetic on repeated assessments

- Any individual not confirmed to have diabetes on repeated assessments is to be assessed for his/her glucose level, and OGTT performed repeatedly, at intervals of months, and his/her clinical course is to be observed closely [1] (grade B; consensus).

\section{Normal and borderline types}

- Annually, less than $1 \%$ of patients with the normal type are shown to progress to the diabetic type [1] (grade B; consensus).

- A large proportion of patients with the borderline type are shown to progress to the diabetic type, and the frequency of atherosclerotic complications is shown to increase in these individuals. Individuals with the borderline type are therefore to receive instructions on lifestyle modification (diet, exercise, and correction of obesity, if present) and be assessed on a regular basis [1] (grade B; consensus).

\section{High normal values in fasting glucose measurements}

- Of those with normal fasting glucose values, those whose fasting glucose value ranges between 100 and $109 \mathrm{mg} / \mathrm{dL}$ are classified as "normal high". It is recommended that these individuals be assessed with an OGTT in an attempt to establish their diagnosis as either normal, borderline or diabetic type [1] (grade B; consensus).

\section{Performing oral glucose tolerance tests (OGTT)}

- Patients are to be given an OGTT solution containing $75 \mathrm{~g}$ of glucose after fasting $10 \mathrm{~h}$ or more and their blood glucose levels are to be measured under fasting conditions at 30- to 60-min intervals following glucose loading. Patients must be assessed for both fasting and 2-h post-OGTT glucose levels and may be assessed for additional glucose levels at a time point in between these two measurements in the clinic. Furthermore, if

Table 3 Criteria of fasting plasma glucose levels and $75 \mathrm{~g}$ oral glucose tolerance test (OGTT) 2-h value

\begin{tabular}{lll}
\hline & Normal range & Diabetic range \\
\hline Fasting value & $<110 \mathrm{mg} / \mathrm{dL}(6.1 \mathrm{mmol} / \mathrm{L})$ & $\geq 126 \mathrm{mg} / \mathrm{dL}(7.0 \mathrm{mmol} / \mathrm{L})$ \\
$75 \mathrm{~g}$ OGTT 2-h value & $<140 \mathrm{mg} / \mathrm{dL}(7.8 \mathrm{mmol} / \mathrm{L})$ & $\geq 200 \mathrm{mg} / \mathrm{dL}(11.1 \mathrm{mmol} / \mathrm{L})$ \\
Evaluation of OGTT & Normal type: if both values belong to normal range & Diabetic type ${ }^{\text {a }}$ if any of the two values falls into diabetic range \\
& Borderline type: neither normal nor diabetic types & \\
\hline
\end{tabular}

Even for normal type, if 1 -h value is $\geq 180 \mathrm{mg} / \mathrm{dL}(10.0 \mathrm{mmol} / \mathrm{L})$, the risk of progression to diabetes mellitus is greater than for $<180 \mathrm{mg} / \mathrm{dL}$ $(10.0 \mathrm{mmol} / \mathrm{L})$ and should be treated as with borderline type (follow up observation, etc.). Fasting plasma glucose level of $100-109 \mathrm{mg} / \mathrm{dL}$ $(5.5-6.0 \mathrm{mmol} / \mathrm{L})$ is called "high-normal'" within the range of normal fasting plasma glucose. Plasma glucose level after glucose load in OGTT is not included in casual plasma glucose levels

${ }^{\text {a }}$ Casual plasma glucose $\geq 200 \mathrm{mg} / \mathrm{dL}(\geq 11.1 \mathrm{mmol} / \mathrm{L})$ and $\mathrm{HbAlc} \geq 6.5 \%$ are also regarded as to indicate diabetic type 


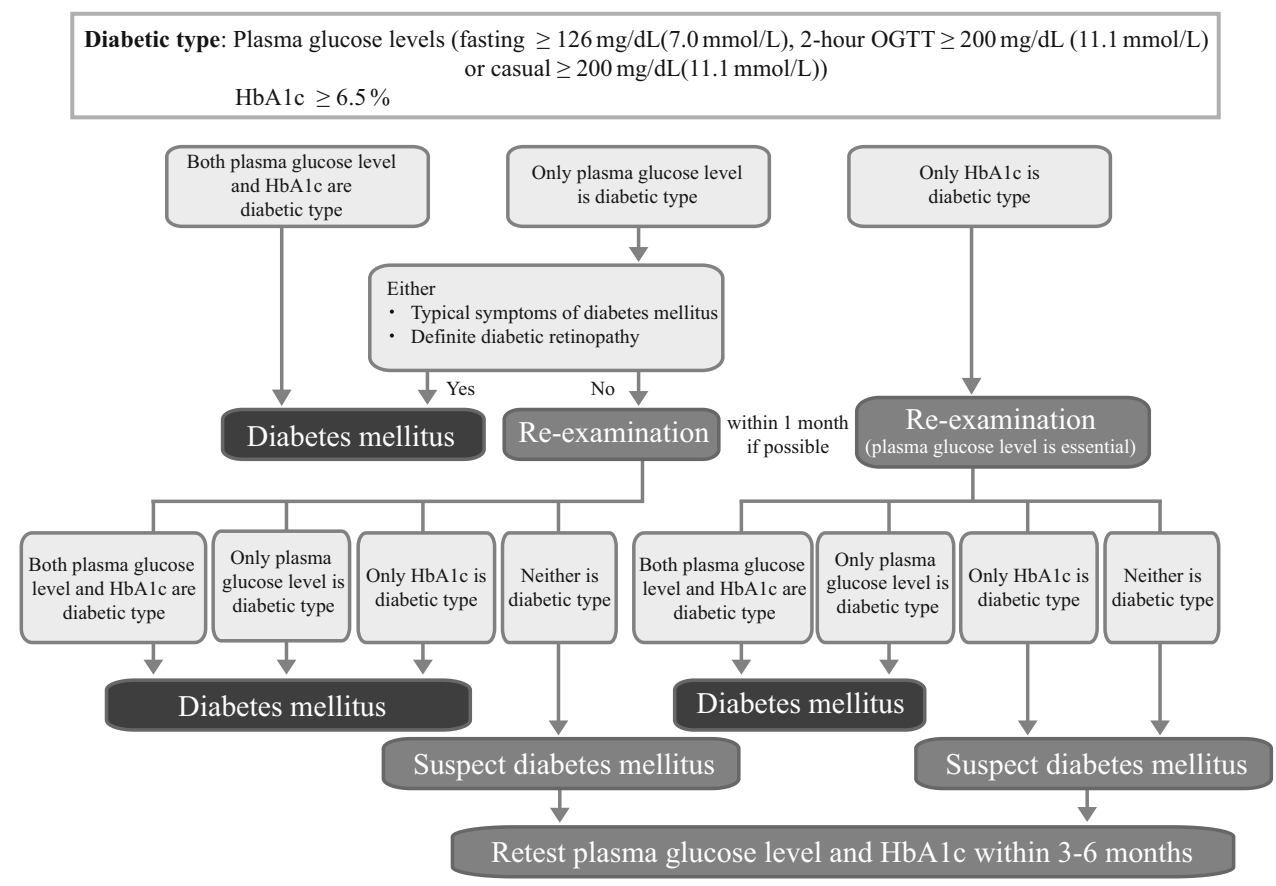

Fig. 1 Flow chart outlining steps in the clinical diagnosis of diabetes mellitus. OGTT Oral Glucose Tolerance Test

\begin{tabular}{|c|c|c|c|c|c|}
\hline \multirow[b]{5}{*}{$\begin{array}{l}\text { Etiology } \\
\text { (mechanism) }\end{array}$} & \multirow{5}{*}{\begin{tabular}{|c} 
Normoglycemia \\
\\
Normal \\
area
\end{tabular}} & \multicolumn{4}{|c|}{ Hyperglycemia } \\
\hline & & \multirow{4}{*}{$\begin{array}{l}\text { Borderline } \\
\text { area }\end{array}$} & \multicolumn{3}{|c|}{ Diabetic area } \\
\hline & & & \multicolumn{2}{|c|}{$\begin{array}{l}\text { Non-insulin-dependent } \\
\text { state }\end{array}$} & $\begin{array}{c}\text { Insulin-dependent } \\
\text { state }\end{array}$ \\
\hline & & & \multicolumn{3}{|c|}{ Need of insulin } \\
\hline & & & not needed & $\begin{array}{c}\text { for glycemic } \\
\text { control }\end{array}$ & for survival \\
\hline \multicolumn{6}{|l|}{ Type 1} \\
\hline \multicolumn{6}{|l|}{ Type 2} \\
\hline Other types & & & & & \\
\hline
\end{tabular}

Fig. 2 A scheme of the relationship between etiology (mechanism) and patho-physiological stages (states) of diabetes mellitus. Arrows pointing right represent worsening of glucose metabolism disorders (including onset of diabetes mellitus). Among the arrow lines, ........... indicates the condition classified as "diabetes mellitus". Arrows pointing left represent improvement in the glucose metabolism disorder. The broken lines indicate events of low frequency. For example, in type 2 diabetes mellitus, infection can lead to ketoacidosis and require temporary insulin treatment for survival. Also, once diabetes mellitus has developed, it is treated as diabetes mellitus regardless of improvement in glucose metabolism, therefore, the arrow lines pointing left are filled in black. In such cases, a broken line is used, because complete normalization of glucose metabolism is rare 
feasible at all, patients should have their glucose levels measured under fasting conditions and $30 \mathrm{~min}$ after glucose loading to evaluate their initial insulin response, for the following reasons (grade A; consensus).

(1) Even those with the normal type are highly likely to progress to the diabetic type if their 1-h post-load glucose levels are high.

(2) Those with the normal/borderline types are likely to progress to the diabetic type if they have a postprandial $0-30$-min insulin increase $(\mu \mathrm{U} / \mathrm{mL})$ to postprandial glucose increase $(\mathrm{mg} / \mathrm{dL})$ ratio $(\Delta \mathrm{IRI} /$ $\Delta \mathrm{PG})$ of 0.4 or lower [2].

9. Classification of diabetes and its relationship to associated metabolic abnormalities

- An etiological classification of diabetes and associated metabolic abnormalities is given below (Fig. 2). Diabetes is classified into type 1 diabetes, type 2 diabetes, due to other specific mechanisms of onset or diseases, and gestational diabetes. Figure 2 describes the relationship between each type of diabetes and the degree of metabolic abnormality associated with each type of diabetes [1] (grade A; consensus).

10. Establishing the type of diabetes present and its complications

- In making a diagnosis, every effort is to be made not only to establish the presence of diabetes, but also to determine the type of diabetes, the degree of metabolic abnormality present, and the presence of associated complications (grade A; consensus).

\section{Goals and strategies for diabetes management}

1. Objectives of diabetes management

- The objectives of diabetes management are to reduce symptoms of diabetes, to prevent development or progression of diabetic complications and disease conditions associated with diabetes, and to enable affected individuals to maintain their quality of life (QOL) and life expectancy comparable to those seen in healthy individuals (grade $\mathrm{A}$; consensus).
2. Goals of glycemic control

- Glucose levels in affected individuals should be controlled as close to normal as possible. Achieving and maintaining favorable glycemic control early after initiation of treatment is likely to lead to favorable longterm outcomes. Improving fasting glucose levels and HbA1c values is critically important for prevention of microangiopathy associated with diabetes, and in addition to these, improving postprandial hyperglycemia is key to prevent of macroangiopathy $[1,2]$ (grade A).

- The goals of glycemic control should be determined individually in light of the patient's age, duration of diabetes, status of complications, risk for hypoglycemia as well as the support system available to address such complications or hypoglycemia. However, the glycemic goal of HbAlc $<7.0 \%$ is recommended to ensure prevention of diabetic complications. In this regard, supportive evidence was available from the Kumamoto Study, [3] in which patients with HbA1c $<6.9 \%$ were found to be less likely to develop microangiopathy.

- In addition to $\mathrm{HbA} 1 \mathrm{c} 7 \%, \mathrm{HbA} 1 \mathrm{c} 6$ and $8 \%$ should also be kept in mind as measures of glycemic control in daily clinical practice. HbA1c $6 \%$ represents the best target in ensuring normalization of glucose levels, ideally, with appropriate diet/exercise therapy alone or with drug therapy without causing adverse events, such as hypoglycemia. This target is set for young individuals with a short duration of diabetes without a past history of cardiovascular disease. In contrast, HbA1c $8 \%$ serves as a measure of glycemic control that needs at least to be achieved in patients in whom intensive therapy is not feasible due to hypoglycemia or other factors as well as the threshold above which treatment needs to be modified or changed to improve glycemic control.

- Given that radical or too stringent glycemic control may often lead to severe hypoglycemia, aggravation of existing microangiopathy or sudden death in some patients, glycemic goals need to be determined individual depending on the disease condition of each patient [4-6] (grade A).

\section{Treatment strategy}

- Treatment strategy for patients with diabetes may vary depending on the type of diabetes, disease condition, 
Fig. 3 Treatment of patients in a non-insulin-dependent state. This provides a guide to the management of patients without acute metabolic disorder (i.e., those who had a casual blood glucose level of 250-300 mg/ dL or less than $250-300 \mathrm{mg} / \mathrm{dL}$ and had a negative test for urine ketone). The glycemic goal should be determined individually depending on the disease condition or age of the patient but is generally set at HbA1c $<7.0 \%$

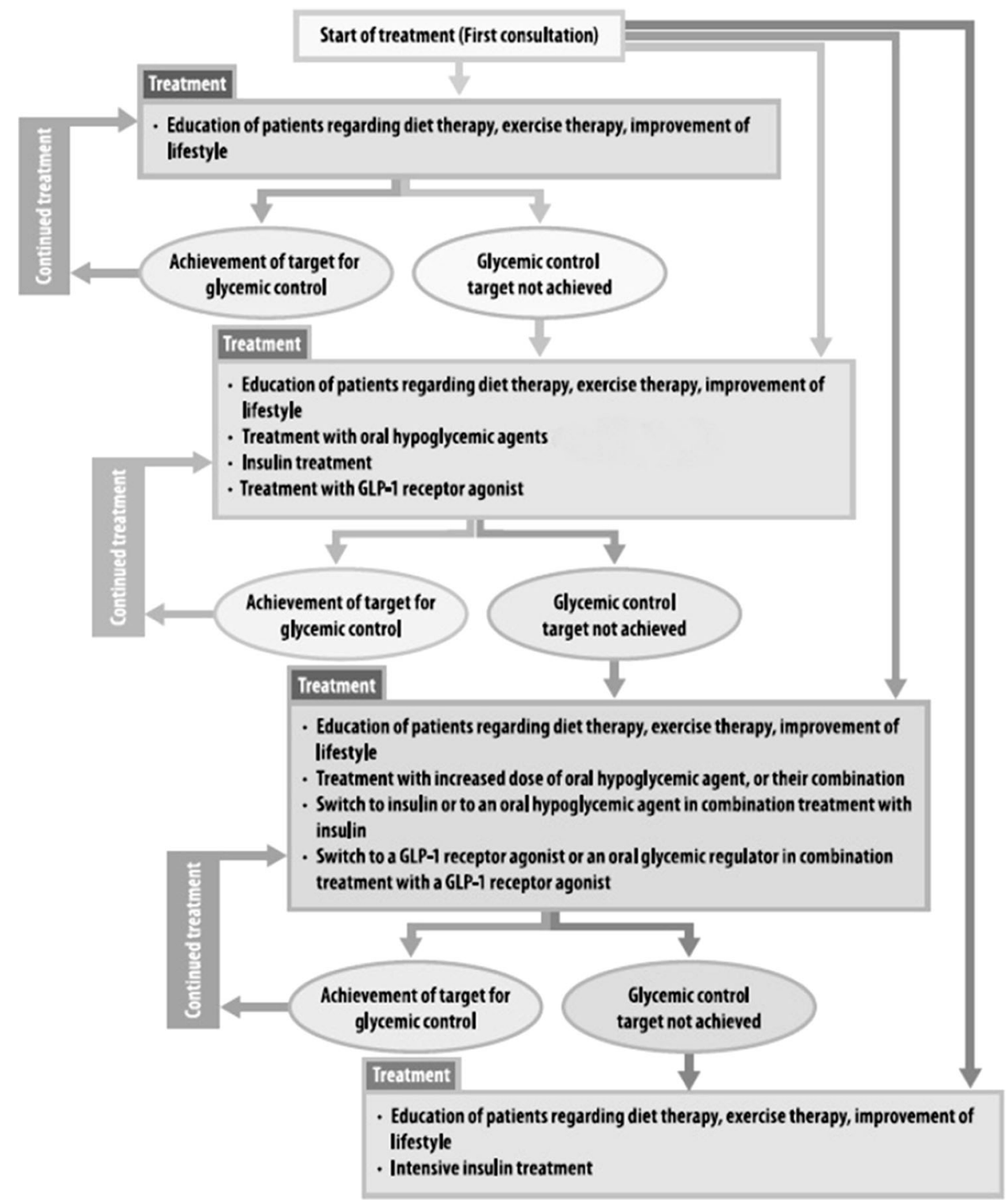

age, extent of metabolic abnormality, and status of diabetic complications (Fig. 3) (grade A; consensus).

- Insulin therapy is to be given not only to patients who are insulin-dependent but also to those in pregnancy, those undergoing surgery which involves whole-body management, or those with severe infection, even if they are not insulin-dependent. In addition, insulin therapy is to be given to those in whom their glycemic goals are not achievable with glucose-lowering agents (grade $\mathrm{A}$; consensus).

- For type 2 diabetes patients in a non-insulin-dependent state, an oral glucose-lowering agent should be initiated if adequate diet/exercise therapy fails to achieve favorable glycemic control within 2-3 months. Depending on the degree of metabolic abnormality,
Table 4 Goals for 1 control of parameters other than glucose

\begin{tabular}{ll}
\hline Parameter & Goal \\
\hline BMI & $22 \mathrm{~kg} / \mathrm{m}^{2}$ \\
$\begin{array}{l}\text { Serum lipid } \\
\text { LDL-cholesterol }\end{array}$ & $\mathrm{CAD}(-):<120 \mathrm{mg} / \mathrm{dL} / \mathrm{CAD}(+):<100 \mathrm{mg} / \mathrm{dL}$ \\
Triglycerides & $<150 \mathrm{mg} / \mathrm{dL}$ \\
HDL-cholesterol & $\geq 40 \mathrm{mg} / \mathrm{dL}$ \\
$\begin{array}{l}\text { Non-HDL- } \\
\text { cholesterol }\end{array}$ & $\mathrm{CAD}(-):<150 \mathrm{mg} / \mathrm{dL} / \mathrm{CAD}(+):<130 \mathrm{mg} / \mathrm{dL}$ \\
\hline
\end{tabular}

$C A D$ Coronary Artery Disease

BMI Body Mass Index

insulin or a glucose-lowering agent should be given in combination with diet/exercise therapy as initial therapy (grade A; consensus). 
4. Prevention of chronic complications or their progression (Table 4)

- In people with obesity, not only glycemic and weight control but blood pressure and lipid control are to be implemented to prevent chronic diabetic complications or their progression. Smoking cessation is also to be adhered to (grade A; consensus).

\section{Importance of continued treatment/education}

- To prevent complications or their progression in diabetes as a chronic disease, continued treatment is essential and patient education by a health care team constitutes the core of diabetes management (grade A; consensus).

\section{Diet therapy}

\section{Diet therapy in general}

- Diet therapy is the cornerstone of therapy for all patients with diabetes. Practicing an appropriate diet improves glycemic control $[1,2]$ (grade A).

\section{Individualized diet therapy}

- Individualized diet therapy according to the lifestyle of each patient is essential for successful introduction and continuation of the recommended diet therapy and requires, first and foremost, that each patient be interviewed adequately about his/her dietary habits, such as food preferences and diet timetables as well as his/her physical activity level (grade A; consensus).

- The elderly are often associated with disturbance of taste, smell, and mastication, reduced secretion of saliva and gastric acid, and impaired renal and hepatic function, which leads to malnutrition and sarcopenia. Therefore, it is required that diet therapy for the elderly be so formulated as to avoid the risk of malnutrition.

3. Diet instructions by registered dietitians

- In clinical practice, diet instructions involving a registered dietitian are useful for glycemic control [3] (grade B).
- The Food Exchange Lists, edited by the Japan Diabetes Society, is commonly used for diet instructions. However, if it is difficult for patients to understand the Food Exchange Lists, actual food products or food models may be used to give instructions (grade B; consensus).

4. Determination of the amount of energy intake

- The amount of energy intake is to be determined by a physician, with consideration given to his/her glucose levels, blood pressure, serum lipid levels, height, body weight, age, sex, complications, and energy expenditure (physical activity) as well as the amount of prior food intake. It must be also determined individually to meet disease conditions of each patient (e.g., setting a lower target for energy intake for obese or elderly patients) (grade A; consensus).

Equations used for calculation of energy intake:

Amount of energy intake $=$ ideal body weight $\times$ physical activity level

Ideal body weight $(\mathrm{kg})=[\text { height }(\mathrm{m})]^{2} \times 22$

Physical activity level (kcal/kg/ideal body weight)

25-30 low-intensity exercise (e.g., jobs involving deskwork)

30-35 moderate-intensity exercise (e.g., jobs involving standing work)

$\geq 35$ high-intensity exercise (e.g., jobs involving heavy physical work)

\section{Composition of macronutrients}

- In formulating a diet for patients with diabetes, it is to be ensured that carbohydrates account for $50-60 \%$ of the total energy [4], while proteins account for $1.0-1.2 \mathrm{~g} / \mathrm{kg} /$ ideal body weight, with the rest of the energy accounted for by fats (grade A).

- Carbohydrates: Given that there is a paucity of evidence as to the intake of carbohydrates in Japan and there is no consensus as to the lower normal limits for carbohydrate intake, it is desirable that carbohydrates not more than $60 \%$ of the total energy intake; that the intake of sweets, jams or soft drinks be minimized as they contain a large amount of sucrose that leads to an elevation of triglyceride levels; and that the intake of fruit be limited to up to 1 unit $(80 \mathrm{kcal}) /$ day, given that fruits currently on markets often contain a large amount of sugar as a result of selective breeding. 
- Proteins: While there is a paucity of evidence for protein intake, it is common practice to recommend $1.0-1.2 \mathrm{~g} / \mathrm{kg} /$ ideal body weight of proteins. Intake of less animal protein and more plant protein (e.g., soybean products) is recommended to prevent atherosclerosis [5]. Protein-restricted diet is recommended for patients with diabetic nephropathy.

- Saturated and polyunsaturated fats: It is recommended that saturated and polyunsaturated fats account for not more than 7 and $10 \%$ of the total energy intake, respectively (grade $\mathrm{B}$; consensus).

- n-3 polyunsaturated fatty acids (e.g., eicosapentaenoic acid [EPA], docosahexaenoic acid [DHA]) which abound in fish are shown to be effective in lowering glucose and triglyceride levels $[6,7]$.

6. Salt intake

- Excessive salt intake may lead to the onset of vascular diseases through elevation of blood pressure as well as to an increase in appetite. Therefore, salt intake should generally be limited, and restricted to $6 \mathrm{~g} / \mathrm{day}$ in patients with diabetes and hypertension and in those with overt nephropathy or more severe disease (grade B; consensus).

\section{Dietary fiber intake}

- Intake of dietary fiber (20-25 g/day) is shown to be effective in improving glycemic control as well as in lowering serum lipid levels (cholesterol and triglycerides) [8] (grade B).

- Daily intake of $350 \mathrm{~g}$ or more of vegetables should be targeted. During meals, taking vegetables first helps to reduce postprandial glucose increases, HbAlc values, and body weight [9].

\section{Intake of varied foodstuffs}

- To avoid vitamin or mineral deficiency, it is to be ensured that patients take as many kinds of food items as possible (grade B; consensus).

\section{Exercise therapy}

1. Initiation of exercise therapy in patients with diabetes and diabetic complications

- Prior to initiating exercise therapy in a patient with diabetes, the patient must be medically assessed for the presence or absence of cardiovascular disease and chronic complications, such as peripheral neuropathy, dysautonomia, advanced retinopathy or orthopedic diseases (grade A; consensus).

- Even in patients with advanced diabetic complications, every effort is to be made to keep their daily physical activity levels from decreasing (grade A; consensus).

2. Exercise therapy in patients with type 2 diabetes

- Exercise improves cardiopulmonary function, [1, 2] glycemic control, [3-7] and lipid metabolism, [5] lowers blood pressure, [5, 7] and increases insulin sensitivity [9-12] (grade A).

- Both aerobic exercise and resistance exercise [3, 13] as well as their combined use [14] is effective for glycemic control (grade A).

- Exercise therapy is expected to be more effective when combined with diet therapy (grade A; consensus).

\section{Exercise therapy in patients with type 1 diabetes}

- If glycemic control is favorable and no advanced complications are present in a patient, any sort of exercise is feasible for this patient with only adjustment of the insulin therapy and supplementary foods administered (grade B; consensus).

- As exercise is expected to offer benefits other than glycemic control such as reducing a patient's risk of developing cardiovascular disease and improving his/ her QOL, exercise of moderate or higher intensity is recommended [15].

- While the long-term effect of exercise on glycemic control remains unclear, exercise reduces the risk factors for cardiovascular disease, [15] and improves QOL [4] (grade B). 
- While exercise of high intensity involving the whole body leads to increased hepatic glucose production, it may also lead to increases in glucose during or after exercise due to impaired glucose utilization in conditions requiring insulin, thus resulting in the onset of ketosis.

4. Exercise therapy for patients with diabetes receiving drug therapy

- Prior to initiating exercise therapy in patients receiving insulin therapy, adjustments are needed such as taking supplementary foods before or during exercise depending on the duration, intensity or amount of exercise involved, based on self-monitoring of blood glucose (SMBG) (grade B; consensus).

- Prior to initiating exercise therapy in patients with glucose lowering agents, particularly sulfonylureas (SU), the drug dose may need to be reduced (grade $\mathrm{B}$; consensus).

5. General precautions for exercise therapy in patients with diabetes

- A close examination of both feet is to be made in every patient to ensure that the shoes chosen for exercise fit their feet perfectly with appropriate cushioning for the entire soles (grade B; consensus).

- When a diabetic patient has poor glycemic control (particularly when both patients with type 1 and type 2 diabetes are found positive for urine ketone body), they are discouraged from doing exercise (grade B; consensus).

- Patients on glucose lowering agents have the risk of developing hypoglycemia during exercise on the day of exercise or the day after exercise. Therefore, it is desirable that these patients, particularly those receiving insulin therapy take 1-2 units of easily absorbable carbohydrates when their glucose levels are less than $100 \mathrm{mg} / \mathrm{dL}$ before exercise (grade B; consensus).

- The amount of exercise should be gradually increased as part of activities of daily living. Warm-up and cooldown exercise should be done before and after exercise (grade B; consensus).

- It is recommended that exercise of moderate intensity be done preferably every day, at least 3-5 times a week for 20-60 min [4] (grade A).

- Exercise-induced improvements in glucose metabolism in patients with diabetes are sustained over a period of 12-72 h after exercise.

\section{Treatment with glucose-lowering agents (excluding insulin)}

1. Indications and non-indications for glucose-lowering agents

- Glucose-lowering agents are indicated for patients with type 2 diabetes failing to achieve favorable glycemic control with adequate diet/exercise therapy of 2-3 months' duration [1-3] (grade A).

- Glucose-lowering agents may be considered for patients whose HbAlc value continues to be $7 \%$ or higher.

- Early use of glucose-lowering agents including insulin is indicated, along with diet/exercise therapy, in patients with type 2 diabetes who require correction of glucotoxicity (grade A; consensus).

- In conditions, such as type 1 diabetes, pregnancy with pre-existing diabetes, diabetic coma, severe infection, surgery requiring whole-body management, in which insulin therapy is an absolute indication, no other glucose-lowering agent should be used for treatment (grade A; consensus).

2. Selection of glucose-lowering agents

- The choice of glucose-lowering agents should be made based on the disease condition of each particular patients with consideration given to the pharmacological and safety profile of each glucose-lowering agent (grade A; consensus).

- The drug dose should be low at first and then increased as required based on monitoring of glycemic control (grade A; consensus).

- Selection of glucose-lowering agents (see Chapter 2, Fig. 3 "Treatment of patients in a non-insulin-dependent state").

Protective effect of glucose-lowering agents against microangiopathy: It is commonly agreed that this inhibitory effect is strongly correlated with the level of glycemic control does not vary between the glucoselowering agents.

Protective effect of glucose-lowering agents against macroangiopathy: This effect is considered to be correlated with the level of glycemic control and varies from one agent to another.

Evidence is available to support the use of metformin (biguanides) in obese patients $[4,5]$. The clinical trials 
that generated relevant evidence vary greatly with regard to their historical background and health care environment as well as the level of healthcare involved. Thus, at present, it remains difficult to evaluate the available evidence, which, in turn, does not allow a clear comparison of the glucose-lowering agents used in the trials.

Dipeptidyl peptidase-4 (DPP-4) inhibitors and Glucagon-like peptide-1 (GLP-1) receptor agonists: No longterm outcome data are available, and their long-term safety remains yet to be established.

\section{Approach to patients with insufficient glycemic} control

- Favorable glycemic control may not be achieved in patients with diabetes on monotherapy with glucoselowering agents [6-8] (grade A).

- In such case, every effort should be made to ensure that diet/exercise therapy is administered exactly as planned (grade A; consensus).

- When the HbA1c level continues to be $7 \%$ or higher in a patient despite treatment with a drug of first choice, the drug dose should be increased.

- In addition, every effort should be made to improve glycemic control with the addition of a glucoselowering agent with a different mechanism of action or by adding, switching to insulin therapy as required (grade A; consensus).

\section{Insulin therapy}

\section{Indications for insulin therapy}

- Patients with Type 1 diabetes, diabetic coma (diabetic ketoacidosis, hyperosmolar hyperglycemic syndrome) and pregnancy with pre-existing diabetes must be in insulin therapy. When diet therapy is not effective, insulin therapy is also recommended when patients are in severe infection and at the time of the surgical procedure with whole-body management is needed (grade A; consensus).

- Relative indications for insulin therapy include the following:

(1) If conspicuous hyperglycemia (e.g., a fasting glucose level of $250 \mathrm{mg} / \mathrm{dL}$ or higher or a casual glucose level of $350 \mathrm{mg} / \mathrm{dL}$ or higher) or a tendency toward ketosis (e.g., positive urine ketones) is noted.

(2) If favorable glycemic control is not obtained with glucose-lowering agents (e.g., primary or secondary sulfonylurea failure).

(3) If adequate glycemic control is not achievable with diet therapy in patients with severe hepatic damage or renal failure.

- Insulin therapy is also used in type 2 diabetic patients when glycemic control is not obtained with diet/ exercise therapy and glucose-lowering agents or when glucotoxicity needs to be resolved in these patients (grade $\mathrm{A}$; consensus).

\section{Risks associated with insulin therapy}

- Insulin therapy may generally be associated with hypoglycemia or aggravation of diabetic retinopathy or neuropathy in some patients [1]. Attention needs also to be given to weight gain as a potential risk associated with long-term insulin therapy [2] (grade A).

- Risk of intensive insulin therapy includes severe hypoglycemia, which is increased as glycemic control improves [3]. To prevent this, appropriate measures against potential hypoglycemia as well as patient education on effective prevention of hypoglycemia based on self-monitoring of blood glucose (SMBG) are required.

- Drastic decline of glycemia may be associated with aggravation of diabetic retinopathy or neuropathy [1].

3. Intensive insulin therapy for type 1 diabetes and its complications

- In type 1 diabetes for which optimal glycemic control is being sought, multiple daily insulin injection (3-4 injections/day) or continuous subcutaneous insulin infusion (CSII) is required [3] (grade A).

- Intensive insulin therapy which combines the above modality with SMBG is shown to be effective in preventing the onset or progression of diabetic microangiopathy (retinopathy, nephropathy, and neuropathy) $[3,4]$ as well as in preventing the progression of diabetic macroangiopathy (ischemic heart disease, cerebrovascular disease, peripheral vascular disease) [5, 6] (grade A). 
4. Type 2 diabetes and insulin therapy

- Rigorous glycemic control is effective for preventing the onset or progression of diabetic microangiopathy in type 2 diabetic patients as well, thus providing the rationale for the use of insulin therapy in type 2 diabetic patients whose glycemic goal cannot be achieved with diet/exercise therapy and glucose-lowering agents $[2,7]$ (grade A).

- While favorable glycemic control may be achieved with once-daily injection of intermediate or long-acting soluble insulin or twice-daily injection of mixed insulin (morning/evening) in patients with mild diabetes, insulin therapy, including intensive insulin therapy with multiple insulin injections, should be used in patients with moderate or severe diabetes $[7,9,10]$ (grade A).

5. Combination therapy with insulin preparations and glucose-lowering agents

- Combination therapy with insulin preparations and glucose-lowering agents (sulfonylureas, [11, 12] biguanides, [13] $\alpha$-glucosidase inhibitors, [14, 15] thiazolidinediones $[16,17])$ is shown to improve glycemic control as well as to reduce the need for insulin. However, its long-term efficacy has not been adequately explored (grade B).

\section{Treatment of diabetic retinopathy}

\section{Diagnosis of retinopathy}

- Once the diagnosis of diabetes has been established in a patient, he/she should be referred to an ophthalmologist to be examined for the presence or absence of diabetic retinopathy $[1,2]$ (grade A).

- Thereafter, the patient should be examined for retinopathy once a year or more frequently if he/ she is at high risk of developing retinopathy (grade A; consensus).

- Retinopathy is often classified based on the David classification into four phases: (1) no retinopathy; simple retinopathy; (3) non-proliferative retinopathy; and (4) proliferative retinopathy. In recent years, however, a new international classification of retinopathy severity levels has been proposed [3].
2. Risk factors for development and progression of retinopathy

- Patients with diabetes who meet any of the following conditions are at high risk of development or progression of diabetic retinopathy (grade A):(1) long duration of diabetes; (2) high HbA1c value; (3) severe retinopathy found at initial diagnosis; (4) presence of hypertension as a concurrent disease; and (5) pregnancy.

\section{Medical treatment of retinopathy}

- Stringent glycemic control inhibits the development or progression of diabetic retinopathy in patients with type 1 and 2 diabetes [4-6] (grade A).

- Treatment of hypertension as a complication associated with diabetes is effective in suppressing the progression of diabetic retinopathy [7] (grade A).

- The Kumamoto Study [5] is the only study that has demonstrated a treatment threshold in HbAlc $(6.9 \%)$ below which there is nearly no risk of diabetic retinopathy. In contrast, the United Kingdom Prospective Diabetes Study (UKPDS) and the Diabetes Control and Complications Trial (DCCT) have shown that the nearer to normal the HbA1c value, the greater the inhibition of the development or progression of diabetic retinopathy with treatment.

\section{Ophthalmological treatment of retinopathy}

- Photocoagulation in patients with non-proliferative and early proliferative retinopathy prevents the development of blindness associated with diabetic retinopathy [8] (grade A).

- Vitrectomy may suppress the progression of severe visual impairment associated with vitreous hemorrhage and retinal detachment and allow normal eyesight to be maintained [9] (grade A).

- Local macular photocoagulation (hereafter macular coagulation), local drug use (steroids, anti-VEGF antibodies) and vitreous surgery are shown to be effective on macular edema $[10,11]$ (grade A).

\section{Pregnancy with pre-existing diabetes}

- Diabetic retinopathy may progress drastically in pregnancy complicated by diabetes, irrespective of gly- 
cemic control. Therefore, pregnant women should be examined for diabetic retinopathy at least at early, middle and late phases of pregnancy.

\section{Treatment of diabetic nephropathy}

1. Diagnosis of diabetic nephropathy

- The diagnosis of early nephropathy is made based on the appearance of microalbuminuria. To assist its detection, urine albumin should be measured in patients with diabetes at least once a year by using spot urine samples (Table 5) (grade A; consensus).

- As an assessment of renal function, in addition to glomerular filtration rate (GFR), the use of estimated GFR (eGFR) as calculated based on serum creatinine or cystatin $\mathrm{C}$ values is also recommended (grade $\mathrm{A}$; consensus).

2. Principles in the treatment of diabetic nephropathy

- Stringent glycemic control prevents the development or progression of diabetic nephropathy [1-3] (grade A).

- Rigorous blood pressure control (target: <130/ $80 \mathrm{mmHg}$ ) prevents the development or progression of diabetic nephropathy [4-7] (grade A).

- In glycemic and blood pressure control in the elderly, their age needs to be taken into account (grade A; consensus)

\section{Prevention of early nephropathy}

- Rigorous glycemic control prevents the development of diabetic nephropathy [1-3] (grade A).

- Rigorous blood pressure control prevents the development of diabetic nephropathy [8] (grade A).

4. Treatment of early nephropathy

- Rigorous glycemic control prevents the progression of diabetic nephropathy in patients with type 1 and 2 diabetes [1-3] (grade A).
- The use of angiotensin-converting enzyme (ACE) inhibitors is reported to inhibit the progression to overt nephropathy in patients with type 1 diabetes with microalbuminuria, and the use of ACE inhibitors is recommended for the treatment of early nephropathy [9, 10] (grade A).

- Blood pressure control with antihypertensive agents (particularly ACE inhibitors, angiotensin II receptor blocker $[\mathrm{ARB}])$ prevents the progression to overt nephropathy $[4,5,11]$ (grade A).

- ACE inhibitors prevents the progressing to overt nephropathy in normotensive patients with diabetes [9, 12] (grade B).

- Patients with diabetes affected by hypertension should be instructed to restrict their salt intake (grade A; consensus).

\section{Treatment of overt nephropathy}

- ACE inhibitor- or ARB-based treatment should be administered to patients with overt nephropathy $[11,13]$ (grade A).

- ACE inhibitors prevent the development of renal dysfunction in patients with type 1 diabetes affected by overt nephropathy [6] (grade A).

- ACE inhibitors and ARBs prevent the development of renal dysfunction in patients with type 2 diabetes and overt nephropathy [7, 13] (grade A).

- In patients with overt nephropathy whose blood pressure cannot achieve to goal with an ACE inhibitor or ARB, other kinds of antihypertensive agents (e.g., longacting calcium antagonists, diuretics) should be given as add-on (grade A).

- Protein-restricted diets potentially suppress the progression of nephropathy in type 1 diabetes [14] (grade B) Patients with type 2 diabetes and overt nephropathy are recommended to be instructed to use proteinrestricted diets (grade B; consensus).

- Patients with diabetes affected by overt nephropathy should be instructed to restrict their salt intake (grade A; consensus).

Table 5 Criteria for diagnosis of diabetic early nephropathy (Joint Committee on Diabetic Nephropathy 2005)

1. Candidates for diagnostic tests: diabetic patients who tested negative or positive $(1+)$ for proteinuria

2. Primary Criteria

Urinary Albumin Creatine Ratio, 30-299 mg/g Cr (spot urine sample) on 2 out of 3 measurements

3. Secondary criteria

Urinary Albumin Excretion Rate, 30-299 mg/24 h (24-h urine collection) or 20-199 $\mu \mathrm{g} / \mathrm{min}$ (1-h urine collection)

Urinary type IV collagen, $7-8 \mu \mathrm{g} / \mathrm{g}$ Cr or higher

Kidney size, hypertrophic 
- In a cohort study of Japanese patients with type 2 diabetes affected by overt nephropathy followed for about 7 years, urinary protein excretion was identified as a risk factor for end-stage renal failure [15]. A similar finding was reported in a sub-analysis of the reduction in endpoints in NIDDM with the angiotensin II antagonist losartan (RENAAL) study [16].

\section{Treatment of diabetic neuropathy}

\section{Diagnosis of diabetic neuropathy}

- Diabetic neuropathy is among the most common complications affecting patients with diabetes. In examining a diabetic patient, it should be ensured that he/she be assessed for the presence or absence of neuropathy as well as for its stage if present (grade A; consensus).

- In making a diagnosis of diabetic neuropathy in a patients with diabetes, he/she should be assessed comprehensively by not only interviewing him/her about neurological symptoms but examining the patient for pain sensation (using toothpicks or bamboo skewers), vibration perception (with diapason C128), pressure sensation (with a monofilament) as well as for Achilles reflex. Findings of foot dryness, rhagades, callositas, and ulceration are useful as suggestive of the presence of neuropathy (grade A; consensus).

- The heart rate variability test is useful for assessment of autonomic function (grade A; consensus).

- Nerve conduction studies are essential for the definitive diagnosis of diabetic neuropathy as well for the diagnosis of asymptomatic neuropathy (grade A; consensus).

- The examinations mentioned above need to be made on a regular basis to follow up diabetic neuropathy over a period of years (grade A; consensus).

\section{Development/progression of diabetic neuropathy}

- Risk factors for the development/progression of diabetic neuropathy include (1) poor glycemic control, (2) duration of diabetes, (3) hypertension, (4) dyslipidemia, (5) smoking, and (6) drinking, [1-3] but the most significant of these is poor glycemic control, and diabetic neuropathy is seen to develop frequently in patients with poor glycemic control [4] (grade A).

- Stringent glycemic control suppresses the development/ progression of diabetic neuropathy [5] Evidence for this benefit is established in type 1 diabetes but less well established in type 2 diabetes [6] (grade A).
- Kumamoto study demonstrated that deterioration of nerve conduction rate and vibration perception threshold was significantly reduced with intensive insulin therapy [7].

3. Basic treatment of diabetic neuropathy

- In treating diabetic neuropathy, not only stringent and maximally useful glycemic control but instructions on lifestyle modification such as abstinence and smoking cessation should be given to patients with diabetes (grade A; consensus).

- In patients in whom hyperglycemia persists over time, neurological symptoms may temporarily appear or worsen with drastic decline of glycemia and need to be watched for (grade A; consensus).

- A majority of these mono-neuropathies resolves spontaneously, however they are often associated with sensory/motor neuropathy. Thus, it is important that patients be given relevant instructions on glycemic control and lifestyle modification.

\section{Treatment of painful neuropathy}

- Mild painful neuropathy becomes alleviated with glycemic control and lifestyle modification. Non-steroidal anti-inflammatory drugs (NSAIDs) are effective in mild painful neuropathy alone. Recommended drugs of first choice for moderate to severe painful neuropathy include tricyclic antidepressants, [8] the $\alpha 2 \delta$ ligand pregabalin, [9] and the selective serotonin-noradrenalin reuptake inhibitor (SNRI) duloxetine [10] (grade B).

\section{Diabetic foot}

1. Regular foot examination in patients with diabetes

- Patients with diabetes should undergo foot examinations on a regular basis for the presence or absence of risk factors for foot ulcers or amputation (grade $\mathrm{A}$; consensus).

- Definition of Diabetic Foot: Internationally, as a working definition, diabetic foot is defined as "infections, ulcers and destructive deep tissue lesions in a patient with diabetes who has diabetic neuropathy and/ or peripheral arterial diseases (PAD)". 
- Foot Examination and Risk Assessment of Foot Ulcers: Patients with diabetes should be examined for presence or absence of neuropathy, PAD, foot deformity, skin lesions and other manifestations. As the severity of diabetic neuropathy cannot be assessed on the basis of medical history or symptoms alone, a detailed examination of neuropathy is needed, based on such tests as vibration testing, pin-prick testing, deep tendon reflex and the Semmes-Weinstein 5.07 (10 g) monofilament.

2. Foot care education to patients with diabetes

- To prevent foot ulcers, foot care education should be given to all patients with diabetes (grade A; consensus).

3. Foot care for patients at high risk of foot ulcer

- Patients with diabetes at high risk of foot ulcer (e.g., those with a history of foot ulcer or amputation or those with PAD or neuropathy) should receive foot examinations and foot care more frequently than those at a lower risk (grade $\mathrm{A}$; consensus).

\section{Treatment of foot ulcer}

- Treatments of foot ulcer include topical therapy, antiinfection therapy, treatment of PAD, off-loading wound care, as well as general care (control of glucose levels, water balance, and nutrition as well as management of heart failure and renal failure) (grade A; consensus).

○ Depending on its etiology (e.g., PAD or neuropathy), sites of ulcers, presence or absence of infection, the treatment of foot ulcer varies. Therefore, the treatment of foot ulcer calls for a multidisciplinary teamapproach involving physicians and other healthcare professionals from divergent backgrounds (e.g., diabetology, dermatology, orthopedics, plastic surgery, cardiology, vascular surgery, radiology, and physiotherapy).

Various pharmacological agents and therapeutic modalities are currently available to promote healing of chronic foot ulcer. However, very few of these have been shown to be beneficial in large-scale randomized controlled trials. Of these, negative-pressure wound therapy has been shown to shorten the time to wound healing in patients undergoing partial foot amputation [1].

\section{Lower extremity amputation (LEA)}

- Prior to performing LEA, blood flow needs to be evaluated at the site where amputation is to be carried out (grade A; consensus).

6. Multidisciplinary team approach for diabetic foot

- The prevention and treatment of diabetic foot should be based on close collaboration between physicians and other healthcare professionals in relevant specialties [2] (grade A; consensus).

- Care of diabetic foot calls for control of overall health, revascularization in severe lower-limb ischemia, local treatment such as debridement of infected tissue, use of offloading devices and therapeutic shoes, walking rehabilitation, and diabetes education. Therefore, forging a team-approach involving experts across disciplines and responsibilities is essential.

\section{Diabetes and periodontitis}

1. Relationship between diabetes and periodontitis

- Diabetes and periodontitis adversely affect each other [1-3] Therefore, patients with diabetes should be informed about their relationship, consult dentists regularly to have themselves examined for oral cavity status and undergo dental care as required (grade $\mathrm{A}$; consensus).

2. Periodontitis in patients with diabetes

- Periodontitis is more frequently seen and severer among patients with diabetes (particularly those with poor glycemic control and at risk of disease progression) than among healthy individuals [1-3] (grade A).

- In a Japanese study comparing patients with diabetes and healthy individuals for prevalence of periodontitis, 
likewise, periodontitis was shown to be higher in prevalence among both patients with type 1 and type 2 diabetes than among healthy individuals [1].

3. Influence of periodontitis on the onset of diabetes and on its disease condition

- Individuals with periodontitis are more likely to have diabetes [4] and are at a higher risk of developing diabetes than those without [5]. Severe periodontitis may adversely affect glycemic control in diabetes if left untreated [2] (grade B; consensus).

- In the Hisayama cohort study, periodontitis was shown to be higher in frequency among those who developed glucose intolerance over a 10-year period than among those who did not [6].

4. Influence of periodontal care on glycemic control

- Periodontal care in type 2 diabetes may lead to improvements in their HbA1c values [7] (grade B).

- A meta-analysis/systematic review suggests that periodontal care in type 1 diabetes has little or no influence on their glycemic control, while periodontal care in type 2 diabetes is shown to improve their HbA1c values by a mean of $0.66 \%$, although this is not significant [8].

- Another meta-analysis/systematic review suggests that periodontal care in type 2 diabetes significantly improves HbAlc by a mean of $0.4 \%$ [9].

- In a Japanese study, periodontal care combined with topical antibiotic therapy is shown to significantly improve glycemic control in type 2 diabetes [7].

\section{Diabetic macroangiopathy}

1. Screening for macroangiopathy

- Screening tests for macroangiopathy include resting electrocardiogram (ECG), chest X-ray, carotid ultrasonography, ankle-brachial index (ABI) and it is desirable that these examinations be performed in patients with diabetes once a year (grade A; consensus).
2. Risk factors for macroangiopathy

- For the prevention of macroangiopathy, it is important that comprehensive control of its risk factors such as diabetes, hypertension, dyslipidemia, obesity and smoking be initiated early and maintained rigorously $[1,2]$ (grade A).

- The frequency of coronary artery disease is shown to increase by 2 - to fourfold among type 1 and type 2 patients with diabetes compared to that among individuals without diabetes.

- Cerebrovascular disease is shown to be higher in incidence among patients with diabetes, with their risk of developing cerebral infarction being 2 times higher than that in non-diabetic individuals [3]. Furthermore, as with coronary artery disease, cerebrovascular disease associated with diabetes has poor prognosis and a high mortality rate [4].

- Likewise, the frequency of PAD is shown to be 4 times higher in patients with diabetes than that in individuals without diabetes as a major cause of gangrene and lower-limb amputation [5].

- The frequency of incidence of macroangiopathy per 1000 persons/year is shown to be $9.6 \%$ coronary artery disease and $6.3 \%$ cerebral infarction in the Japan Diabetes Complications Study (JDCS) [6] and $4.4 \%$ coronary artery disease and $3.1 \%$ cerebral infarction in the Japan Diabetes Clinical Data Management study (JDDM) [7].

\section{Lifestyle modification and resolution of obesity}

- Diet, exercise and lifestyle modification such as smoking cessation are the cornerstone of therapy for diabetic macroangiopathy [8,9]. Obesity should be resolved, if present in patients with diabetes. (for obesity resolution goals, see chapter 13, "Diabetes Complicated by Obesity") (grade A).

4. Rigorous Stringent glycemic, blood pressure, and lipid control and drug-based prevention of macroangiopathy

- Stringent glycemic control is effective in inhibiting the development and progression of diabetic macroangiopathy [10] (for glycemic goals, see chapter 2, 
"Goals and Strategies for Diabetes Management") (grade A).

- In glycemic control, the risk of macroangiopathy is shown to be reduced to a greater extent with metformin than with sulfonylurea- or insulin-based therapy [11]. Metformin is shown to effective in protecting against cardiovascular disease in an observational study which included Japanese patients [12].

- Rigorous Stringent blood pressure control is shown to alleviate the risk of developing diabetic macroangiopathy in patients with diabetes [13, 14] (for blood pressure goals, see chapter 14, "Hypertension Associated with Diabetes") (grade A).

- Hydroxymethylglutaryl-CoA (HMG-CoA) reductase inhibitors or "statins" are shown to be effective for both primary and secondary prevention of coronary artery disease and cerebral infarction [15] (for lipid goals, see chapter 15, "Dyslipidemia Associated with Diabetes") (grade A).

- However, acute glucose normalization, severe hypoglycemia, and excessive blood pressure lowering may increase mortality or the risk of diabetic macroangiopathy in patients at high risk [16-18] (grade A).

5. Use of antiplatelet agents

- Use of antiplatelet agents is effective for secondary prevention of diabetic macroangiopathy [19, 20] (grade A).

\section{Diabetes complicated by obesity}

\section{Diabetes complicated by obesity}

- Obesity, particularly visceral obesity, is an important risk factor that promotes the development and progression of diabetes. Weight loss should therefore be a priority in the treatment of diabetes complicated by obesity (grade A; consensus).

\section{Assessment of obesity}

- Obesity as a physical condition is defined as a BMI of $25 \mathrm{~kg} / \mathrm{m}^{2}$ or higher, as distinct from that associated with conditions, such as diabetes, requiring medical measures for weight loss [1] (grade A).

- Visceral obesity is frequently associated with dyslipidemia and hypertension, both of which are risk factors for atherosclerosis. A BMI of $22 \mathrm{~kg} / \mathrm{m}^{2}$ or less is generally thought to represent a weight loss target which is less likely to be associated with health problems; however, it is desirable that the BMI target as part of diabetic treatment be determined based on each particular patient's disease condition and lifestyle (grade A; consensus).

\section{Causes of obesity}

- The most common cause of obesity is simple obesity (excluding secondary obesity, e.g., endocrinologically, neurologically or genetically determined obesity or drug-induced obesity) due to overeating and lack of physical activity (grade $\mathrm{B}$; consensus).

- If the patient is thought likely to have primary obesity after due consideration to secondary obesity as a possibility, the patient should be interviewed about the environmental or psychological factors involved, and every effort should be made to ensure that any lifestyle habit thought to be responsible for obesity is removed or alleviated. The patient should be sufficiently informed about obesity, in particular visceral obesity, which, if it persists and becomes associated with not only hyperglycemia but dyslipidemia and hypertension, places him/her at high risk of developing atherosclerotic diseases, thus motivating the patient for weight loss (grade B; consensus).

\section{Treatment of obese type 2 diabetes}

- In obese patients with type 2 diabetes, priority should be given to weight loss through diet/exercise therapy. If diet/exercise therapy does not lead to sufficient improvements in glycemic control in the patient, drug therapy should be considered. Treating hyperglycemia with drugs in an obese diabetic patient while leaving obesity untreated may lead to aggravation of obesity in the patient. Thus, every effort should be made to ensure lifestyle modification so that glycemic control can be obtained without causing weight gain in obese patients with diabetes (grade B; consensus).

- The use of insulin or sulfonylureas should be minimized in obese patients with type 2 diabetes (grade C; consensus).

- Uncritical use of these agents may further aggravate the existing obesity in these patients [2,3] (grade C).

- Surgical therapy for obesity, such as laparoscopic sleeve gastrectomy, laparoscopic Roux-en-Y gastric 
Table 6 Recommended clinical laboratory examinations
Urine: albumin or protein, glucose, occult blood, urinary sediment

Blood chemistry: glucose, HbA1c, lipids, liver/renal function

Electrolytes, chest X-ray, electrocardiogram (ECG) bypass, and laparoscopic adjustable gastric banding are available for use in severe obesity with comorbidity, all of which are, however, not yet covered by insurance, with only laparoscopic sleeve gastrectomy approved as advanced medical care in January 2010 for use in combination with other insurance-covered modalities at designated healthcare institutions.

\section{Metabolic syndrome}

- Metabolic syndrome, which is diagnosed when 2 or more of such conditions as fating hyperglycemia, dyslipidemia and elevated blood pressure are present in addition to visceral fat accumulation, has been put forward as a syndrome of interest in the prevention of atherosclerotic diseases, as well as a target for prevention of diabetes since it is frequently associated with insulin resistance or glucose intolerance. Patients with the metabolic syndrome should be encouraged to reduce visceral fat through lifestyle modification (see also chapter 24. "The Metabolic Syndrome") (grade B; consensus).

\section{Hypertension associated with diabetes}

1. Treatment of hypertension in diabetes

- Blood pressure control should be initiated from an early stage of diabetes, together with glycemic and lipid control, in patients with diabetes [1,2] (grade A).

- In treating hypertension in patients with diabetes whose blood pressure is $130 / 80 \mathrm{mmHg}$ or higher, as a rule, treatment with antihypertensive agents, together with lifestyle modification, should be initiated [2,3] (grade A).

- Lifestyle modification without medication can be continued up to 3 month. However, treatment with antihypertensive agents should be initiated in these patients if lifestyle modification fails to achieve the blood pressure goals set for these patients [3] (grade B).

- Patients with diabetes should be assessed for diabetic microangiopathy as well as for its severity. Patients with diabetes should also be assessed for other risk factors for hypertension and targeted organ damages, as well as cardiovascular disease.
- Clinical laboratory examinations (Table 6) should be performed in routine clinical practice. Brain MRI, carotid ultrasonography, ultrasonic cardiography (UCG), or ABI may be performed as required to assess the severity of atherosclerosis.

2. Goals for blood pressure lowering

- The blood pressure goal should be set at less than 130/80 mmHg [4, 5] (grade A).

- A meta-analysis of 13 studies evaluating the systolic blood pressure goal of $135 \mathrm{mmHg}$ or less in patients with impaired glucose tolerance (IGT) or diabetes on intensive therapy and $140 \mathrm{mmHg}$ or less in those on standard therapy [5] suggested a $10 \%$ decrease in mortality in those on intensive therapy as well as a continued decrease in incidence of stroke that lasted until a systolic blood pressure of $120 \mathrm{mmHg}$ was achieved. Given the higher incidence of stroke in Japan compared to that in western countries and the evidence demonstrating the effectiveness of blood pressure control to less than $130 / 80 \mathrm{mmHg}$ in prevention of stroke, the blood pressure goal for patients with diabetes and hypertension has been recommended as less than 130/80 $\mathrm{mmHg}$.

- Adequate blood pressure lowering should be ensured in patients with diabetic nephropathy $[1,4,6]$ (grade A).

- In patients with coronary heart disease (CHD), consideration should be given to ensuring that blood pressure lowering is not carried to extremes $[4,5,7,8]$ (grade B).

3. Choice of antihypertensive agents

- ACE inhibitors and ARBs should be used as drugs of first choice [6-10] (grade A).

- The ARBs are shown to reduce the incidence of newonset diabetes [12]. Similar effects are also suggested for the ACE inhibitors.

- In the Microalbuminuria cardiovascular renal outcomes heart outcomes prevention evalution (MICRO-HOPE) study in which patients with hypertension accounted for 
Table 7 Goals for lipid control by risk category

\begin{tabular}{|c|c|c|c|c|c|}
\hline \multirow[t]{2}{*}{ Treatment policy } & \multirow[t]{2}{*}{ Risk category } & \multicolumn{4}{|c|}{ Goal for lipid control (mg/dL) } \\
\hline & & LDL-C & HDL-C & TG & non-HDL-C \\
\hline \multirow[t]{3}{*}{ Primary prevention: Consider drug therapy after lifestyle modification } & I & $<160$ & \multirow[t]{3}{*}{$\geq 40$} & \multirow[t]{3}{*}{$<150$} & $<190$ \\
\hline & II & $<140$ & & & $<190$ \\
\hline & III & $<120$ & & & $<150$ \\
\hline Secondary prevention: Consider drug therapy along with lifestyle modification & With prior CAD & $<100$ & & & $<130$ \\
\hline
\end{tabular}

$L D L-C$ LDL-cholesterol, $H D L-C$ HDL-cholesterol, $T G$ triglycerides, $C A D$ coronary artery disease. Adapted from reference [5]

Use the relative risk chart in motivating those with a low absolute risk (e.g., young patients) for lifestyle modification, while at the same time monitoring for changes in absolute risk in these patients. All values given above are intended as goals for lipid control. It is also important to lower LDL-C level by 20-30\%. The goals for non-HDL-C are of secondary interest and are relevant only after achievement of the goals for LDL-C in those with hypertriglyceridemia. Non-HDL-cholesterol should be used when triglycerides are shown to be $400 \mathrm{mg} / \mathrm{dL}$ or higher or when postprandial blood was sampled in these patients. In all risk categories, lifestyle modification remains the cornerstone of therapy in achieving the goals for lipid control. In category I, LDL-C $180 \mathrm{mg} / \mathrm{dL}$ or higher serves as a basis for considering drug therapy

$56 \%$ of the study population, the ACE inhibitors were shown to reduce the incidence of cardiovascular disease by $25 \%$ [6]. Similarly, of the ARBs, losartan has been shown to reduce mortality from cardiovascular disease by $37 \%$ compared to $\beta$-blockers.

In patients with inadequate blood pressure lowering with ACE inhibitors or ARBs, their dose should be increased or a long-acting dihydropyridine calcium channel blockers' (CCBs) or low-dose thiazide diuretics should be added [8, 11, 12] If this proves ineffective, combination therapy with three agents should be given to these patients (grade A).

- The use of diuretics, $\beta$-blockers or long-acting dihydropyridine CCBs are shown to reduce the incidence of cardiovascular disease such as stroke or heart disease in patients with diabetes and hypertension [13].

\section{Dyslipidemia associated with diabetes}

1. Role of anti-dyslipidemic therapy in patients with diabetes

- Dyslipidemia should be aggressively treated in patients with diabetes. Diabetes is a strong, independent risk factor for the development of cardiovascular disease. Dyslipidemia associated with diabetes further increases the risk of cardiovascular disease, whereas, its resolution leads to a decrease in the incidence of cardiovascular disease [1] (grade A).
- Japanese patients with diabetes with LDL-cholesterol $160 \mathrm{mg} / \mathrm{dL}$ or higher are placed at 3.7-fold risk of ischemic heart disease (IHD) compared to those with LDL-cholesterol less than $100 \mathrm{mg} / \mathrm{dL}$ [2, 3].

2. Goals for lipid control

- Dyslipidemia in patients with diabetes should be treated based on the lipid control goals listed in Table 7 [4] (grade A).

\section{Effectiveness of lifestyle modification}

- Diet therapy and exercise therapy are expected to improve glycemic and lipid metabolism (grade A; consensus).

\section{Drug therapy}

- In patients in whom the lipid control goals cannot be achieved even after improvements in lifestyle and glycemic control, drug therapy should be considered (grade $\mathrm{A}$; consensus).

- HMG-CoA reductase inhibitors or "statins" are drugs of first choice for elevated LDL-cholesterol $[1,2,6]$ (grade A).

- Fibrates are drugs of first choice for hypertriglyceridemia [6] (grade A).

- Eicosapentaenoic acids (EPA) are also indicated for hypertriglyceridemia [7]. 
Table 8 Definition and diagnostic criteria of gestational diabetes

Definition of gestational diabetes

Glucose metabolism that is abnormal, but less so than in diabetes, and that is first detected, or occurs first, during pregnancy

Diagnostic criteria

In $75 \mathrm{~g}$ OGTT, gestational diabetes is diagnosed if at least one of the following conditions is met

Fasting plasma glucose

Plasma glucose 1-h after a meal

Plasma glucose 2-h after a meal

Those women who had clinically diagnosed diabetes are excluded from the diagnosis of GDM

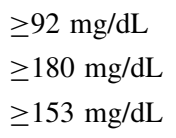

Table 9 Management for planned-pregnancy
Achievement and maintenance of HbA1c less than $7.0 \%$
Comprehensive education on diet therapy, etc. glucose monitoring, and insulin therapy
Assessment and treatment of diabetes retinopathy, nephropathy and neuropathy
Switching from glucose-lowering agents to insulin
Discontinuation of ACE inhibitors, ARBs, statins, and fibrates

\section{Impaired glucose metabolism in pregnant women}

1. Impaired glucose metabolism in pregnant women

- Impaired glucose metabolism in pregnancy includes pregnancy in pre-existing diabetes and hyperglycemic disorders in pregnancy. The latter consists of gestational diabetes mellitus (GDM) and overt diabetes in pregnancy (grade A; consensus).

- Definition and diagnostic criteria of GDM in pregnancy are shown in Table 8 (grade A; consensus).

- Fulminant type 1 diabetes may occur as a rare form of impaired glucose metabolism during pregnancy (grade B; consensus).

2. Pre-pregnancy glycemic control

- Poor glycemic control in an early stage of pregnancy is associated with an increase in frequency of congenital anomalies or miscarriage, [1] which, however, can be prevented by tight glycemic control initiated before pregnancy [2] (grade A).

- Advanced chronic diabetic complications in a pregnant woman may affect her delivery outcome and prognosis [3] (grade A).

- Planned pregnancy with adequate pre-pregnancy glycemic control (Table 9) should be performed to prevent congenital anomalies or miscarriage, and not to adversely affect healthy child development and longterm prognosis of the mother.
3. Diabetic retinopathy

- Diabetic retinopathy may be aggravated during pregnancy and therefore needs to be assessed for its presence before pregnancy and closely monitored during pregnancy [4]. Given that proliferative/pre-proliferative retinopathy is particularly highly likely to worsen during pregnancy, a woman who desires to become pregnant should be encouraged to have her retinopathy treated and resolved at an ophthalmologist before becoming pregnant [5] (grade A).

\section{Diabetic nephropathy}

- Urinary excretion of albumin/protein increases during pregnancy, thus increasing the risk for pregnancy-induced hypertension and premature delivery. Therefore pregnant women with diabetic nephropathy need to be closely monitored [6] (grade A).

- Women with impaired renal function are at risk of further renal impairment during pregnancy and have a poor peripartum prognosis. They should be given careful counseling regarding pregnancy [7] (grade B).

5. Screening for gestational diabetes mellitus (GDM)

- It is desirable that all pregnant women be screened for GDM with a glucose test as a standard procedure, [8] at their initial visit and at gestational 24-28 weeks. A $75 \mathrm{~g}$ OGTT should be performed in all women who tested positive at a prior glucose test to establish the diagnosis of GDM (grade A). 
6. Glycemic control during pregnancy

- The objective of glycemic control during pregnancy is to prevent the development of peripartum complications and macrosomia. Thus, tight glycemic control is critically important [9] (grade A).

- Required glucose levels should be as close as possible to within the normal diurnal glycemic variation range. In addition, the risk of hypoglycemia should be minimized. The glucose target should be as follows: a fasting glucose level of $70-100 \mathrm{mg} / \mathrm{dL}$, 2-h postprandial glucose level of less than $120 \mathrm{mg} / \mathrm{dL}$ (grade A; consensus).

- Frequent SMBG is desirable to ensure tight glycemic control [10] (grade A).

\section{Diet therapy}

- Diet therapy should be aimed at ensuring providing pregnant women with necessary and sufficient nutrition, thereby promoting healthy child development as well as ensuring tight glycemic control and appropriate weight gain in these women (grade A).

\section{Insulin therapy}

- Insulin therapy should be given in pregnant women in whom the glycemic goals cannot be achieved with diet therapy alone. As the use of glucoselowering agents is not recommended, ${ }^{11}$ they should be switched to insulin therapy (grade A; consensus).

- Intensive insulin therapy with $\mathrm{SMBG}$ is preferable in pregnant women to ensure tight glycemic control. Multiple daily insulin injection and CSII are shown to be not different in efficacy [12].

- While it is shown that the use of rapid insulin analogues and regular insulin in pregnant women do not differ significantly in their influence on their fetuses, [13] the safety of insulin glulisine remains yet to be established (grade A).

- The long-acting insulin analogue insulin detemir can be used in pregnant women, [14] but, at present, the safety of insulin glargine in pregnant women remains yet to be established (grade B).

\section{Exercise therapy}

- There is no evidence that provide the rationale for encouraging exercise therapy among pregnant women with GDM (grade C; consensus).
10. Delivery and post-delivery management

- The term and mode of delivery should follow usual obstetric indications. However, vaginal delivery may be avoided in some patients with advanced proliferative retinopathy (grade $\mathrm{B}$; consensus).

- Neonates from mothers with GDM should be monitored, and if they are found to have complications or to be at high risk of developing complications, they should be transferred to the neonatal intensive care unit (NICU) (grade A; consensus).

- Breastfeeding is recommended (grade A; consensus).

11. Reassessment of mothers with GDM for glucose tolerance

- Women with GDM should be reassessed for glucose tolerance with a $75 \mathrm{~g}$ OGTT 6-12 weeks after delivery (grade B; consensus).

- All women with a history of GDM are at high risk of developing diabetes and therefore need to be followed up [15] (grade A).

\section{Pediatric/adolescent diabetes}

\section{Fundamental considerations}

- The treatment of pediatric/adolescent diabetes should take into account the age and developmental status of each patient, with due consideration also given to their mental instability or insecurity (grade A; consensus).

- The required energy intake for these patients should be calculated based on Table 10, and in reference to their ideal body weight.

2. Type 1 diabetes in children and adolescents

\section{1) Goals of treatment}

- The goals of treatment are to prevent diabetic complications through glycemic control and to maintain socially and mentally healthy status in children and adolescents with type 1 diabetes (grade A; consensus).

\section{2) Insulin therapy}

- Insulin injections are indispensable for type 1 diabetes and therefore should be initiated as soon as a patient has been diagnosed with type 1 diabetes (grade A; consensus). 
Table 10 Dietary Reference Intakes: Estimated Energy Intakes (kcal/day)

\begin{tabular}{|c|c|c|c|c|c|c|}
\hline \multirow{2}{*}{$\begin{array}{l}\text { Sex } \\
\text { Physical activity level }\end{array}$} & \multicolumn{3}{|l|}{ Male } & \multicolumn{3}{|l|}{ Female } \\
\hline & I & II & III & I & II & III \\
\hline \multicolumn{7}{|l|}{ Age } \\
\hline $0-5$ months & - & 550 & - & - & 500 & - \\
\hline $6-8$ months & - & 650 & - & - & 600 & - \\
\hline 9-11 months & - & 700 & - & - & 650 & - \\
\hline $1-2$ years & - & 1,000 & - & - & 900 & - \\
\hline $3-5$ years & - & 1,300 & - & - & 1,250 & - \\
\hline $6-7$ years & 1,350 & 1,550 & 1,700 & 1,250 & 1,450 & 1,650 \\
\hline $8-9$ years & 1,600 & 1,800 & 2,050 & 1,500 & 1,700 & 1,900 \\
\hline $10-11$ years & 1,950 & 2,250 & 2,500 & 1,750 & 2,000 & 2,250 \\
\hline $12-14$ years & 2,200 & 2,500 & 2,750 & 2,000 & 2,250 & 2,550 \\
\hline 15-17 years & 2,450 & 2,750 & 3,100 & 2,000 & 2,250 & 2,500 \\
\hline $18-29$ years & 2,250 & 2,650 & 3,000 & 1,700 & 1,950 & 2,250 \\
\hline \multicolumn{7}{|l|}{ Pregnancy/lactation } \\
\hline \multicolumn{7}{|l|}{ Pregnant women (add) } \\
\hline Early phase & & & & +50 & +50 & +50 \\
\hline Middle phase & & & & +250 & +250 & +250 \\
\hline Late phase & & & & +450 & +450 & +450 \\
\hline Lactating women (add) & & & & +350 & +350 & +350 \\
\hline
\end{tabular}

Values for adults were calculated by using the equation: estimated energy intake $=$ basal metabolic rate $(\mathrm{kcal} /$ day $) \times$ physical activity level. The physical activity levels for individuals aged 18-29 years are defined as: $\mathrm{I}=1.50$; $\mathrm{II}=1.75$; and III $=2.00$. Data source: "Dietary Reference Intakes for Japanese" Development Committee. Report of the "Dietary Reference Intakes for Japanese" Development Committee, Ministry of Health, Labour and Welfare, Tokyo, 2009

- The glycemic goals for adults are also used for patients 18 years old or older [1]. As insulin resistance is shown to increase physiologically during puberty, the insulin dose (/kg body weight) for patients is often increased during puberty compared to that before puberty [2].

\section{3) Diet therapy}

- The point of diet therapy does not lie in dietary restriction. Rather, diet therapy is aimed at providing patients with necessary and sufficient nutrition for normal development and growth, as adjusted by age and sex (grade A; consensus).

\section{4) Exercise therapy}

- In the absence of advanced diabetic complications, and as long as stable glycemic control is obtained in patients, they are encouraged to participate in all kinds of sports available (grade A; consensus).

\section{5) Hypoglycemia}

- Hypoglycemia may induce cognitive dysfunction [3, 4]. Patients younger than 7 years old may be unaware of hypoglycemic episodes and develop severe hypoglycemia, and this needs to be kept in mind (grade A).

- From puberty onward, not only hypoglycemia but poor glycemic control and persistent hyperglycemia are associated with the onset of cognitive dysfunction in adolescents [4] (grade B).

\section{Type 2 diabetes in children and adolescents}

\section{1) Diagnosis}

- In a glucose loading test for diagnosis of type 2 diabetes in children and adolescents, the amount of glucose to be loaded is calculated with the equation: measured weight $\times 1.75 \mathrm{~g}$ (upper limit, $75 \mathrm{~g}$ ). The hyperglycemic categories and criteria for diabetes for children and adults are the same as those for adults (grade A; consensus). 


\section{2) Goals of treatment}

- As in pediatric/adolescent type 1 diabetes, the goals of treatment are to prevent diabetic complications through glycemic control and to maintain socially and mentally healthy status in type 2 diabetic children and adolescents (grade A; consensus).

- Prevention of microangiopathy and macroangiopathy in young adults requires initiation of intervention directed at the risk factors responsible for their aggravation [5] (grade A).

\section{3) Diet therapy}

- The point of diet therapy does not lie in dietary restriction. Rather, diet therapy is aimed at providing patients with necessary and sufficient energy for normal development and growth, as adjusted by age and sex (grade A; consensus).

- In obese patients, the amount of energy intake should be adjusted to 90-95\% of the energy required for their ideal body weight (grade A; consensus).

\section{4) Exercise therapy}

- Every effort should be made to increase physical activity levels and energy expenditure in pediatric/adolescent patients with type 2 diabetes to improve insulin resistance (grade $\mathrm{A}$; consensus).

\section{5) Treatment with glucose-lowering agents}

- In patients whose glycemic goals cannot be achieved with diet/exercise therapy alone, glucose-lowering agents should be initiated (grade B; consensus).

- In patients with ketoacidosis or those in whose adequate glycemic control cannot be achieved with glucose-lowering agents, insulin therapy should be used (grade A; consensus).

- Patients with type 2 diabetes should also be treated for hypertension and dyslipidemia if they are found to have these conditions as well (grade B; consensus).

\section{Diabetes (and bone metabolism) in the elderly}

1. Diabetes in the elderly

- Diabetes increases in frequency with aging [1] (grade A).

- Diabetes in the elderly is a risk factor for diabetic microangiopathy, [2] macroangiopathy, [3] dementia,
[4] depression, [5] and decreased activities of daily living (ADL), [6] and fractures [7] (grade A).

- In the elderly, treatment policy needs to be individually determined with the patient's status in mind. Glycemic control is difficult to achieve in patients with many comorbidities.

2. Diagnosis of diabetes in the elderly

- The same procedures and reference values are used for the diagnosis of diabetes in the elderly. However, elderly patients are frequently diagnosed as having diabetes based on HbA1c, 2-h post-load glucose levels, and hyperglycemia on casual blood glucose measurements, even when they fail to meet the diagnostic criteria for fasting glucose levels [8] (grade A).

3. Diet/exercise therapy in the elderly

- In the elderly as well, both diet therapy [9] and exercise therapy $[10,11]$ are effective treatments for diabetes [12]. Continued exercise is shown to be useful for prevention of macroangiopathy and dementia, as well as for maintenance and improvement of ADL (grade A).

4. Drug therapy and hypoglycemia in the elderly

- In the elderly as well, drug therapy is an effective treatment for diabetes [13, 14] (grade B).

- Severe hypoglycemia associated with drug therapy is likely to occur in elderly patients, [15] particularly those aged 75 years old or older, [16] and in conjunction with conditions such as multi-drug therapy, immediately after discharge, renal failure, and decreased dietary intake. The elderly tend to be less aware of hypoglycemic episodes as they occur and present with atypical complaints. Severe hypoglycemia increases the risk of dementia [17] (grade B).

- It is accepted that biguanides should be given to elderly patients with caution [18] (grade C).

5. Characteristics of diabetes in the elderly and precautions in treatment

- A high proportion of elderly patients with diabetes are likely to have difficulty being independent and taking care of themselves [6] due to vascular complications, particularly macroangiopathy, 
decreased ADL and cognitive function associated with diabetes. The glycemic goal for an elderly patients should be based on his/her disease condition and other physical, mental and social factors rather than based on evidence from randomized controlled trials (RCTs) that established the efficacy of tight glycemic control. On the other hand, it is suggested that the HbA1c goal should be set $1 \%$ higher for frail elderly patients than that for other age groups [19] and that attention should be given to ensuring that glucose lowering is not too drastic for these patients [19] (grade A).

- In elderly patients as well, every effort should be made to optimize glucose, blood pressure and lipid levels, and body weight to prevent the development/progression of micro- and macroangiopathy. In elderly patients for whom maintenance and improvement of their QOL is a priority, attention should be given to ensuring that diabetes treatment does not lead to decreases in their QOL (grade A; consensus)

6. Bone metabolic disorders associated with diabetes

- Bone strength is accounted for by two factors, i.e., bone mass and bone quality. While bone mass is shown to be increased, [20] rather than decreased, in diabetes, diabetic patients are at high risk of developing fractures [7] (grade A).

- The use of thiazolidinediones places female patients at increased risk of developing fractures [21] (grade B).

- The use of alendronate is associated with increases in bone mass, [22] and decreases in fracture risk (grade B).

\section{Acute metabolic complications of diabetes}

1. Diabetic ketoacidosis (DKA)

\section{1) Diagnosis}

- Diabetic ketoacidosis (DKA) is defined as a state in which a severe shortage of insulin and an increase in counter regulatory hormones combine to induce hyperglycemia $(\geq 250 \mathrm{mg} / \mathrm{dL})$, hyperketonemia (increased $\beta$-hydroxy-butyric acid), and acidosis $(\mathrm{pH},<7.30$; bicarbonate concentration, $<18 \mathrm{mEq} / \mathrm{L}$ ) requiring emergency care [1] (grade A; consensus).

\section{2) Treatment}

- Patients with DKA are to be given water and sodium supplementation with saline-based infusions [1] (grade A; consensus).

- It is important to ensure appropriate potassium supplementation in patients with DKA [1] (grade A; consensus).

- Acidosis is not to be corrected in patients with DKA [1, 2] (grade A).

- Low-dose insulin (intravenous infusion of regular insulin) is to be given continuously to patients with DKA (grade A; consensus).

\section{3) Complications associated with DKA}

- Patients with DKA may be associated with brain edema, hyperchloremic metabolic acidosis, and hypokalemia, and should therefore be monitored for consciousness, vital signs, and electrolytes over time during the course of treatment (grade A; consensus).

2. Hyperosmolar hyperglycemic state (HHS)

\section{1) Diagnosis}

- Hyperosmolar hyperglycemic state (HHS) is likely to occur when patients with type 2 diabetes become hyperglycemic due to infection, cerebrovascular disease, surgery, high-calorie infusions, and inappropriate use of diuretics or steroids. While HHS is known to be common in the elderly, it is also drawing attention as an initial symptom of pediatric type 2 diabetes (particularly in African-Americans) (grade A; consensus).

- HHS leads to varying levels of impaired consciousness, polydipsia due to dehydration, polyuria, and general malaise but its onset is slower than DKA with the time to onset of disease being a few days or a week (grade A; consensus).

- Patients with HHS exhibit hyperglycemia ( $\geq 600 \mathrm{mg}$ / $\mathrm{dL})$ and a hyperosmolar state $(\geq 320 \mathrm{mOsm} / \mathrm{L})$ but do not have acidosis $(\mathrm{pH}, \geq 7.30$; bicarbonate concentration, $\geq 18-20 \mathrm{mEq} / \mathrm{L}$ ) (grade A; consensus).

\section{2) Treatment}

- Patients with HHS are to be given water and sodium supplementation with saline-based infusions (grade A; consensus). 
- As in patients with DKA, patients with HHS are to be treated with intravenous infusion of regular insulin [1] (grade A; consensus).

\section{3) Complications associated with HHS}

- Patients with HHS may be associated with brain edema, pneumonitis, gastrointestinal hemorrhage, renal failure, cerebrovascular disease, pulmonary thrombosis, and hypokalemia and should therefore be monitored for consciousness, vital signs, and electrolytes over time during the course of treatment (grade A; consensus).

\section{Lactic acidosis}

\section{1) Diagnosis}

- Lactic acidosis is defined as a state of metabolic acidosis that results from a marked increase in blood lactic acid ( $>5.0 \mathrm{mmol} / \mathrm{L})$ associated with lactic acid overproduction or impaired lactic acid metabolism that require emergency care (grade A; consensus).

- While lactic acidosis is reported to have developed in patients receiving biguanides, a majority of these patients were those in whom biguanides had been a contraindication or their careful administration had been indicated in the first place (grade A; consensus).

\section{2) Treatment}

- In patients presenting with tissue hypoxia, adequate tissue perfusion and oxygenation are to be ensured (grade A; consensus).

- Patients with lactic acidosis are to be treated for any underlying diseases present (grade A; consensus).

- Patients with lactic acidosis are to be treated with oxygen supplementation, artificial respiration, extracellular fluid supplementation or vasopressors drug, depending on their disease condition (grade A; consensus).

- Hemodialysis is reported to be effective in improving lactic acidosis associated with the use of biguanides [3] (grade C).

\section{Hypoglycemia}

\section{1) Prevention of hypoglycemia}

- Given that hypoglycemia remains a major obstacle to diabetes treatment, it is recommended that patients at risk receive education on its prevention and preventive measures and learn to use self-monitoring of blood glucose (SMBG) (grade A; consensus).

\section{2) Diagnosis of hypoglycemia and treatment}

- If a patient presents with palpitation, sweat, faintness or a decreased level of consciousness and has a glucose level of $70 \mathrm{mg} / \mathrm{dL}$ or lower, the patient is to be diagnosed as having hypoglycemia and treated accordingly. As a preliminary measure, patients with potential hypoglycemia are encouraged to have their glucose levels measured (e.g., using a SMBG device) (grade A; consensus).

- If a patient has been confirmed to have hypoglycemia, the patient is to be immediately given carbohydrates (equivalent to 5-10 g of glucose) orally, an intravenous infusion of glucose (equivalent to 10-20 g of glucose), or an intramuscular injection of glucagon. Patients with a history of hypoglycemia are at risk of recurrent or prolonged hypoglycemia even after recovery from hypoglycemia and therefore need to be monitored closely with appropriate measures taken against hypoglycemic episodes (grade A; consensus).

\section{3) Asymptomatic hypoglycemia}

- Recurrent hypoglycemia may induce a decrease in counter regulatory hormone response as well as asymptomatic hypoglycemia. To prevent this, it is important to take measures to avoid hypoglycemic episodes and maintain favorable glycemic control on a routine basis (grade $\mathrm{A}$; consensus).

\section{4) Drug-induced hypoglycemia}

- Of the oral glucose-lowering agents, long-acting sulfonylureas, in particular, are likely to cause hypoglycemia (grade A; consensus).

- Of the insulin preparations, rapid-acting insulin analogues and long-acting soluble insulin analogues are thought less likely to be associated with hypoglycemia than conventional regular insulin and intermediate insulin [4] (grade B).

- Intensive insulin therapy is shown to increase severe hypoglycemia by about threefold in frequency compared to conventional therapy. Therefore, the goal for glycemic control needs to be determined for each patient depending on his/her disease condition [5] (grade $\mathrm{A})$. 


\section{Diabetes, infectious diseases and sick days}

1. Diabetes and susceptibility to infection

- Patients with diabetes showing poor glycemic control are susceptible to bacterial, tuberculous and fungal infection, which, in turn, tend to become severe (grade A; consensus).

- Next to malignant neoplasms and vascular diseases, infectious diseases are the third most common cause of death $(14.3 \%)$ in Japanese patients with diabetes, [1] with the age at death from infections shown to be younger in those with poor glycemic control than in those with favorable glycemic control [1].

2. Glycemic control in the presence of infection

- In the presence of infection, glucose levels tend to increase in patients with diabetes, and this increase in glucose makes them less resistant to the infection. Therefore, insulin should be used to maintain favorable glycemic control in these patients during the treatment of infection requiring hospitalization (grade A; consensus).

3. Diabetes and influenza (including that by pandemic influenza [H1N1]2009)

- Patients with diabetes are at high risk of death from influenza and secondary pneumonia. Thus, seasonal influenza vaccination is recommended in patients in whom vaccination is not contraindicated. Patients with diabetes should be instructed to immediately seek medical consultation, undergo relevant examinations and receive appropriate treatment if influenza is suspected because of a high fever or a chill (grade A; consensus).

\section{Sick-days}

- A sick-day may be defined as a time when patients with diabetes have a fever, diarrhea or vomiting or are unable to eat due to appetite loss. During such sick-days, special measures are required to avoid hyperglycemia or ketoacidosis (grade A; consensus).

- Patients with diabetes should be instructed in daily clinical practice to consult their physicians about how to manage their sick-days and not to act on their own judgment (e.g., discontinue insulin or OHAs or reduce their dose too much if they are on insulin or glucoselowering agents).

- During sick-days, glucose levels tend to increase in patients on insulin, despite limited dietary intake, through the influence of insulin-antagonistic hormones. Therefore, it is important to drink water and continue insulin therapy even during sick-days, while adjusting the insulin dose.

- Immediate medical consultation is required when the patient

(1) has a fever and severe gastrointestinal symptoms

(2) is unable to eat/is able to eat only a small amount of food for a 24 -h period

(3) has positive urinary ketones or glucose level $\geq 350 \mathrm{mg} / \mathrm{dL}$

(4) has altered mental status

At the time of consultation, the patient should be assessed for urine ketone body.

\section{Diabetes and pancreas/islet transplantation}

\section{Pancreas transplantation}

- Pancreas transplantation is indicated for insulin-dependent patients with diabetes in whom glycemic control is extremely difficult. In patients with renal failure undergoing simultaneous pancreas-kidney transplantation (SPK), the proportion of patients discontinuing insulin therapy 5 years later was shown to be high at about $70 \%$, suggesting the usefulness of SPK $[1,2]$ (grade B).

- Pancreas transplantation alone has only a limited indication, as it is associated with a poorer graft survival rate than that with SPK [1] (grade C).

- SPK is associated with improved life prognosis and renal graft survival rates, as compared to those with kidney transplantation alone (KTA) [3].

- As with SPK, pancreas transplantation after kidney transplantation (PAK) is associated with improved life prognosis and renal graft survival rates, as compared to those with KTA [4] (grade C).

- Normalization of glycemia with pancreatic transplantation leads not only to improved QOL but reduces micro- and macroangiopathy $[5,6]$ (grade C).

- Survival rate and pancreatic graft survival rate for 5 years are 95.5 and $71.6 \%$ in Japan, respectively [2]. 
- In Japan, the Organ Transplant Law went into effect in 1997 and pancreatic transplantation has been included for insurance coverage since April 1, 2006.

\section{Islet transplantation}

- Islet transplantation is a tissue transplant procedure through which pancreatic islets are isolated and infused into the liver via the portal vein. This procedure is being investigated as a potential therapeutic modality for patients with favorable renal function who experience recurrent episodes of asymptomatic hypoglycemia or severe hypoglycemia and in whom glycemic control is difficult to achieve. While the proportion of patients discontinuing insulin therapy is low, this procedure is shown to improve glycemic control and reduce hypoglycemia [7] (grade C).

- As with SPK and PAK, islet transplantation after renal transplantation is shown to provide renal graft protection [8] (grade C).

- In patients undergoing pancreatic removal for chronic pancreatitis or pancreatic injury, autologous islet transplantation is shown to be useful for post-removal glycemic control [9] (grade C).

\section{Diabetes self-management education}

\section{Diabetes self-management education and its effectiveness}

- Diabetes self-management education is effective for achieving/maintaining favorable metabolic control and preventing the development and progression of diabetic complications [1-3] (grade A).

2. Diabetes self-management education

by a multidisciplinary team

- A multidisciplinary team approach involving relevant experts enhances outcomes of diabetes self-management education [1, 4] (grade A).

- It is desirable that responsibilities are appropriately divided, and relevant information and goals shared, among the experts involved to allow continued collaboration in various settings (grade A; consensus).

- A multidisciplinary team is to consist of a variety of healthcare professionals, who include nurses, dieticians, pharmacists, clinical laboratory technicians, physical therapists, clinical psychologists if available, and social workers, in addition to physicians in relevant specialties. While all members are allowed to give an outline of diabetes care, they are to turn to relevant experts for a discussion of details.

3. Involvement of specially trained diabetes educators

- Diabetes education involving specially trained nurses and other healthcare professionals is shown to be effective for improving a patient's knowledge of diabetes, self-care ability, and attitude (e.g., motivation and orientation) as well as for glycemic control, at least, in the short term [5] (grade A).

- Experts participating in a multidisciplinary team may also be expected to play a role as a case manager or coordinator [4] (grade A).

- Certified diabetes educators in Japan are defined as all licensed nurses, dieticians, pharmacists, clinical laboratory technicians, and physical therapists, who qualified for and passed a diabetes educator examination and were certified by the Certification Board for Diabetes Educators in Japan.

4. Standardized curricula meeting a set of specific standards

- Standardized group training programs are shown to be useful when they intend to promote continued patient self-care behavior and meet a set of specific standards [2]. Patient self-care behavior include self-management of diet/exercise therapy, beneficial stress management, drug adherence, self-monitoring, and selfmanagement of acute/chronic diabetic complications (grade A).

\section{Importance of self-monitoring of diabetes}

- As diabetes remains largely asymptomatic, selfmonitoring of diabetes by patients is useful for their self-management. Preferably, instructions aimed at promoting self-monitoring of diabetes should address how they should self-monitor diabetes and determine goals for self-monitoring, as well as how they may translate self-monitoring into self-care behavior [1, 6-8]. Major topics of interest to self-monitoring of diabetes include SMBG, and documentation of body 
weight/meals taken, physical activity (pedometer measurement) and blood pressure (grade A).

- SMBG is essential for the maintenance of glycemic control in all patients with type 1 diabetes [1] (grade A).

- $\mathrm{SMBG}$ is shown to be effective for improving glycemic control as well as for promoting diabetes self-management education in patients with type 2 diabetes receiving insulin therapy, [6] while this remains to established in patients with type 2 diabetes not receiving insulin therapy [9] (grade A).

- $\mathrm{SMBG}$ is essential for ensuring tight glycemic control in most patients with gestational diabetes as well as in patients with diabetes in pregnancy [7] (grade A).

- SMBG is essential for ensuring the safe treatment of patients with diabetes less or not sensitive to hypoglycemic episodes, and the use of hypoglycemia awareness programs is effective [8] (grade A).

6. Increasing patient potential for diabetes selfmanagement and mental support

- The process of helping patients to explore and exploit their self-managing potential is best defined as empowerment. It is beneficial to appreciate the patients' psychosocial aspects based on mutual trust, to explore opportunities for their initiative and participatory involvement by means of open questions, and to help them solve care-related problems and make informed decisions [10] (grade A).

- In empowering patients, it is required to watch for changes in their behavior and to provide with timely, behaviorally-oriented assistance as well as psychological support [11, 12] (grade A).

7. Need for assessment of diabetes self-management education

- While diabetes self-management education can be assessed for its effects directly by questioning the patients being educated about improvements in their diabetes knowledge/skills, changes in their behavior and their behavioral processes, ultimately, diabetes care education needs to be assessed for outcome in terms of medical records, patient QOL and prognosis as well as medical costs [1, 4] (grade B).

- Multidisciplinary DMSE teams are to be assessed for their effects in terms of their structure, processes, and outcomes (grade B; consensus).
8. Putting treatment guidelines into practice and disseminating their use

- "Treatment Guide for Diabetes" edited by the JDS is a practical guide to putting the evidence-based guidelines compiled by the JDS into clinical practice; and it is thought to be useful in standardizing diabetes care and promoting collaboration within teams and between local healthcare institutions, in that it allows diabetes care to be customized to meet the needs of each team or facility, while at the same allowing delivery of consistently uniform diabetes care (grade B; consensus).

- Timely delivery of DMSE or counseling by telephone or on the Internet is effective in empowering patients and healthcare professionals for diabetes care [13] (grade B).

\section{Prevention of type 2 diabetes}

1. Screening of at-risk individuals for prevention of type 2 diabetes

- Patients with IGT are at high risk of developing diabetes. Regular examinations are recommended in those aged 45 years old or older as well as in individuals with obesity. Who are physically inactive, or have a family history of diabetes, a history of gestational diabetes or delivery of a macrosomia, a history of hypertension, dyslipidemia, polycystic ovarian syndrome, disease conditions that induce insulin resistance, cardiovascular disease, or IGT even when younger than 45 years old [1] (grade A; consensus).

- As IGT and diabetes are shown to be present not only individuals with a fasting glucose level of $110 \mathrm{mg} / \mathrm{dL}$ or higher but also in 25-40\% of "normal-high" individuals with a fasting glucose level of 100-109 mg/dL, $75 \mathrm{~g}$ OGTTs are recommended in these groups.

- The risk of developing diabetes is shown to increase by 31.9-fold in Japanese who showed both impaired fasting glucose (IFG) (fasting glucose levels, 100-125 mg/ dL)and HbA1c levels 5.7-6.4\%, compared to those with normal glucose tolerance and HbA1c levels [2].

\section{Instructions on lifestyle modification}

- It is recommended that total energy intake be optimized, and body weight reduced by $5-10 \%$ through lifestyle 
modification, in high-risk patients associated with IGT and overweight/obesity [1] (grade A; consensus).

- It is suggested that dietary fiber-rich unrefined grains, low-glycemic index (GI) foods, [3, 4] green leafy vegetables, [5] and fish [6] may be effective in protecting against diabetes (grade $\mathrm{A}$ ).

- Of the lifestyle intervention studies conducted to date for diabetes prevention, a Japanese intervention study demonstrated that lifestyle intervention reduce the onset of diabetes in an IGT population [7].

- Lifestyle intervention in Japanese subjects with IFG also has been shown to lead to prevention of type 2 diabetes in these individuals [8]

\section{Instructions on exercise therapy}

- Individuals at risk are recommended to do aerobic exercise such as walking for $150 \mathrm{~min} /$ week [9] (grade A).

- Exercise is shown to prevent the development of diabetes, independently of weight loss [9] (grade A).

\section{Instructions on preference modification}

- Smoking is an independent risk factor for the development of diabetes [10] (grade D).

- While light to moderate drinking is shown to reduce the onset of diabetes, [11] even moderate drinking is reported to be a risk factor for the development of diabetes in Japanese lean adults [12]. It is thus recommended to limit drinking to a moderate amount (25 g of alcohol per day) (grade B).

- While coffee intake is highly likely to be a preventive factor for the development of diabetes, [13] evidence available to support this is not strong enough to include it among the recommendations (grade C).

- Quantity of sleep [14] and depression [15] are also shown to be associated with the development of diabetes (grade B).

\section{Clinical research into drug therapy-based prevention}

- Some oral glucose-lowring agents (e.g., biguanides, $\alpha$ glucosidase inhibitors), anti-obesity drugs, antihypertensive agents, lipid-lowering agents, estrogen hormone replacement therapy have been shown to protect against the development of diabetes [16-19]. However, some of these drugs pose concern over their long-term safety (grade B).

\section{Metabolic syndrome}

1. Metabolic syndrome: its concept

- The metabolic syndrome is defined as a clustering in individuals of risk factors for the development of atherosclerosis and type 2 diabetes, which include visceral obesity, insulin resistance/hypertension, dyslipidemia (e.g., hypertriglyceridemia, low HDLcholesterolemia), and elevated blood pressure [1-3] (grade A; consensus).

2. Diagnostic criteria for the metabolic syndrome (Table 11)

- Visceral fat accumulation plays a major role in the metabolic syndrome [2, 3] (grade B; consensus).

- Waist circumference serves as a measure of estimated visceral fat accumulation, and a screening measure based on visceral fat volume estimation for prevention of atherosclerosis [2] (grade B; consensus).

- Japanese diagnostic criteria for metabolic syndrome include increased waist circumference as an essential criterion [4].

3. Clinical implications of the metabolic syndrome

- The risk of developing type 2 diabetes is shown to increase in individuals with the metabolic syndrome by three to sixfold compared to those without the metabolic syndrome [5] (grade A).

- The risk of cardiovascular morbidity and mortality is shown to be 1.5 - to 2-fold higher in those with the metabolic syndrome, compared to those in those without the metabolic syndrome [5] (grade B).

4. Treatment of the metabolic syndrome

- The metabolic syndrome is treated to prevent associated cardiovascular disease and type 2 diabetes [2, 3] (grade B).

- The cornerstone of treatment for the metabolic syndrome is lifestyle modification such as diet/exercise therapy and smoking cessation [6] (grade B). 
Table 11 Diagnostic criteria for the metabolic syndrome

\begin{tabular}{|c|c|c|c|c|c|c|}
\hline Component & $\begin{array}{c}\text { Joint Statement } \\
(2009)\end{array}$ & $\begin{array}{c}\text { Japanese Criteria } \\
(2005)\end{array}$ & $\begin{array}{l}\text { IDF } \\
(2005)\end{array}$ & $\begin{array}{c}\text { AHA/NHLBI (NCEP-R) } \\
(2005)\end{array}$ & $\begin{array}{l}\text { NCEP ATP III } \\
(2001)\end{array}$ & $\begin{array}{c}\text { WHO } \\
(1999)\end{array}$ \\
\hline \multirow[t]{2}{*}{$\begin{array}{l}\text { Essential } \\
\text { component }\end{array}$} & & $\begin{array}{l}\text { Visceral } \\
\text { (intraperitoneal) fat } \\
\text { accumulation }\end{array}$ & Central obesity & & & Insulin resistance \\
\hline & & $\begin{array}{l}\text { Waist circumference: } \\
\text { Male } \geq 85 \mathrm{~cm} \\
\text { Female } \geq 90 \mathrm{~cm} \\
\text { (equivalent in either to } \\
\text { a visceral fat area of } \geq \\
100 \mathrm{~cm}^{2} \text { ) }\end{array}$ & $\begin{array}{l}\text { Waist circumference } \\
\text { Male } \geq 85 \mathrm{~cm} \\
\text { Female } \geq 90 \mathrm{~cm} \\
\text { (criteria for Japanese) }\end{array}$ & & & $\begin{array}{l}\text { Association with IGT or } \\
\text { diabetes and/or presence } \\
\text { of insulin resistance }\end{array}$ \\
\hline Diagnostic criteria & & $\begin{array}{l}\text { If two or more of the } \\
\text { following criteria are } \\
\text { met }\end{array}$ & $\begin{array}{l}\text { If two or more of the } \\
\text { following criteria are } \\
\text { met }\end{array}$ & $\begin{array}{l}\text { If three or more of the } \\
\text { following criteria are } \\
\text { met }\end{array}$ & $\begin{array}{l}\text { If three or more of the } \\
\text { following criteria are met }\end{array}$ & $\begin{array}{l}\text { If two or more of the } \\
\text { following criteria are met }\end{array}$ \\
\hline Abdominal obesity & $\begin{array}{l}\text { Race- and country- } \\
\text { specific criteria }\end{array}$ & & & $\begin{array}{l}\text { Waist circumference } \\
\text { Male } \geq 102 \mathrm{~cm} \\
\text { Female } \geq 88 \mathrm{~cm}\end{array}$ & $\begin{array}{l}\text { Waist circumference } \\
\text { Male } \geq 102 \mathrm{~cm} \\
\text { Female } \geq 88 \mathrm{~cm}\end{array}$ & $\begin{array}{l}\text { Waist-to-hip ratio } \\
\text { Male }>0.9 \\
\text { Female }>0.85 \\
\text { or } \\
\text { BMI } \geq 30 \mathrm{~kg} / \mathrm{m}^{2} \\
\text { or } \\
\text { Waist circumference } \\
\geq 94 \mathrm{~cm}\end{array}$ \\
\hline $\begin{array}{l}\text { TG } \\
\text { HDL-C }\end{array}$ & & $\begin{array}{l}\geq 150 \mathrm{mg} / \mathrm{dL}^{*} \\
\text { and/or }\end{array}$ & & & & \\
\hline SBP & $\begin{array}{l}\text { Male }<40 \mathrm{mg} / \mathrm{dL}^{*} \\
\text { Female }<50 \mathrm{mg} / \mathrm{dL}^{*} \\
\geq 130 \mathrm{mmHg} \\
\text { or }\end{array}$ & $\begin{array}{l}<40 \mathrm{mg} / \mathrm{dL}^{*} \\
\text { in either sex } \\
\geq 130 \mathrm{mmHg}^{*} \\
\text { and/or }\end{array}$ & $\begin{array}{l}\text { Male }<40 \mathrm{mg} / \mathrm{dL}^{*} \\
\text { Female }<50 \mathrm{mg} / \mathrm{dL}^{*} \\
\geq 130 \mathrm{mmHg}^{*} \\
\text { or }\end{array}$ & $\begin{array}{l}\text { Male }<40 \mathrm{mg} / \mathrm{dL}^{*} \\
\text { Female }<50 \mathrm{mg} / \mathrm{dL}^{*} \\
\geq 130 \mathrm{mmHg} \\
\text { or }\end{array}$ & $\begin{array}{l}\text { Male }<40 \mathrm{mg} / \mathrm{dL} \\
\text { Female }<50 \mathrm{mg} / \mathrm{dL} \\
\geq 130 \mathrm{mmHg} \\
\text { or }\end{array}$ & $\begin{array}{l}\text { Male }<35 \mathrm{mg} / \mathrm{dL} \\
\text { Female }<39 \mathrm{mg} / \mathrm{dL} \\
\geq 140 \mathrm{mmHg} \\
\text { or }\end{array}$ \\
\hline DBP & $\geq 85 \mathrm{mmHg}$ & $\geq 85 \mathrm{mmHg}^{*}$ & $\geq 85 \mathrm{mmHg}^{*}$ & $\geq 85 \mathrm{mmHg}^{*}$ & $\geq 85 \mathrm{mmHg}$ & $\geq 90 \mathrm{mmHg}$ \\
\hline FPG & $\geq 100 \mathrm{mg} / \mathrm{dL}$ & $\geq 110 \mathrm{mg} / \mathrm{dL}^{*}$ & $\begin{array}{l}\geq 100 \mathrm{mg} / \mathrm{dL}^{*} \\
\text { or } \\
\text { prior diabetes }\end{array}$ & $\geq 100 \mathrm{mg} / \mathrm{dL}^{*}$ & $\geq 110 \mathrm{mg} / \mathrm{dL}^{*}$ & \\
\hline Microalbuminuria & & & & & & $\begin{array}{l}\geq 20 \mu \mathrm{g} / \mathrm{min} \\
\quad \text { or } \\
\geq 30 \mathrm{mg} / \mathrm{g} \cdot \mathrm{Cr}\end{array}$ \\
\hline
\end{tabular}

$T G$ triglycerides, $H D L-C$ HDL-cholesterol, $S B P$ systolic blood pressure, $D B P$ diastolic blood pressure, $F P G$ fasting plasma glucose, $I D F$ Inernational Diabetes Federation, AHA/NHLBI American Heart Association/National Heart, Lung, and Blood Institute, NECEP ATP III National Cholesterol Education Program's Adults Treatment Panel III, WHO World Health Organaization

* If the patient is receiving drug therapy for hypertriglyceridemia, low HDL-cholesterolemia, hypertention or diabetes, he/she is to be handled accordingly

- Even a weight loss of 5-10\% is shown to significantly alleviate the metabolic syndrome and reduce the incidence of new-onset diabetes, suggesting that reducing visceral fat leads to reductions in the incidence of cardiovascular events [6] (grade B).

Conflict of interest Naoko Tajima has received speaker honoraria from pharmaceutical companies Takeda Pharmaceutical Co., Ltd., and Nippon Boehringer Ingelheim Co., Ltd., Daisuke Yabe has received grants of clinical research from pharmaceutical companies Nippon Boehringer Ingelheim Co., Ltd., and Eli Lilly and Company, Yukihiro Fujita has received travel expenses from pharmaceutical companies Novo Nordisk Pharma Ltd., Takeda Pharmaceutical Co., Ltd., and Sanofi K.K., Masakazu Haneda has received speaker honoraria from pharmaceutical companies Nippon Boehringer Ingelheim Co., Ltd., Mitsubishi Tanabe Pharma Corporation, Novo Nordisk Pharma Ltd., Daiichi-Sankyo Co., Ltd., Taisho Pharmaceutical Co., Ltd., Sanofi K.K., Merck Sharp \& Dohme, Astellas Pharma Inc., Kyowa Hakko Kirin Co., Ltd., Kowa Pharmaceutical Co., Ltd., Takeda Pharmaceutical Co., Ltd., and Novartis Pharma K.K., scholarship grants from Astellas Pharma Inc., Daiichi-Sankyo Co., Ltd., Mitsubishi Tanabe Pharma Corporation, Takeda Pharmaceutical Co., Ltd., Novo Nordisk Pharma Ltd., Merck Sharp \& Dohme, Nippon Boehringer Ingelheim Co., Ltd., and Eli Lilly and Company,
Mitsuhiko Noda, Hideki Origasa, Hiroshi Noto, Atsushi Goto, Kei Fujimoto, Masaya Sakamoto have no conflict of interest.

Human rights statement and Informed consent This article does not contain any studies with human or animal subjects performed by the any of the authors.

\section{References}

\section{Methods for developing the "Diabetes Guideline 2013"}

1. International Diabetes Federation Clinical Guideline Task Force: Global Guideline for Type 2 Diabetes. Brussels: International Diabetes Federation. 2005.

2. National Collaborating Centre for Chronic Conditions: Type 2 Diabetes. National Clinical Guideline for Management in Primary and Secondary Care (Update). London: Royal College of Physicians of London. 2008.

3. Clinical and Scientific Section of the Canadian Diabetes Association: Canadian Diabetes Association 2008 Clinical Practice Guidelines for the Prevention and Management of Diabetes in Canada. Can J Diabetes 2008;32 (Suppl 1): S1-201. 
4. American Diabetes Association: ADA Clinical Practice Recommendations 2012. Diabetes Care. 2012;35 (Suppl 1): S1-110.

1 Guideline for the diagnosis of diabetes mellitus

1. Seino Y, Nanjo K, Tajima N, et al. Report of the Committee on the Classification and Diagnostic Criteria of Diabetes Mellitus. The Committee of the Japan Diabetes Society on the diagnostic criteria of diabetes mellitus. Diabetol Int 2010;1:2-20.

2. Kosaka K, Kuzuya T, Yoshinaga H, et al. A prospective study of health check examinees for the development of non-insulindependent diabetes mellitus: relationship of the incidence of diabetes with the initial insulinogenic index and degree of obesity. Diabet Med 1996;13:S120-126 (level 2).

2 Goals and strategies for diabetes management

1. Stratton IM, Adler AI, Neil HA, et al. Association of glycaemia with macrovascular and microvascular complications of type 2 diabetes (UKPDS 35): prospective observational study. BMJ 2000;321:405-12.

2. Tominaga $\mathrm{M}$, Eguchi $\mathrm{H}$, Manaka $\mathrm{H}$, et al. Impaired glucose tolerance is a risk factor for cardiovascular disease, but not impaired fasting glucose: the Funagata Diabetes Study. Diabetes Care 1999;22:920-24.

3. Ohkubo Y, Kishikawa H, Araki E, et al. Intensive insulin therapy prevents the progression of diabetic microvascular complications in Japanese patients with non-insulin-dependent diabetes mellitus: a randomized prospective 6-year study. Diabetes Res Clin Pract 1995;28:103-17.

4. Inzucchi SE, Bergenstal RM, Buse JB, et al. Management of hyperglycemia in type 2 diabetes: a patient-centered approach: position statement of the American Diabetes Association (ADA) and the European Association for Study of Diabetes (EASD). Diabetes Care 2012;35:1364-79.

5. Gerstein HC, Miller ME, Byington RP, et al. (Action to Control Cardiovascular Risk in Diabetes Study Group). Effects of intensive glucose lowering in type 2 diabetes. $\mathrm{N}$ Engl $\mathrm{J}$ Med 2008;358:2545-59.

6. Patel A, MacMahon S, Chalmers J, et al. (ADVANCE Collaborative Group). Intensive blood glucose control and vascular outcomes in patients with type 2 diabetes. $\mathrm{N}$ Engl J Med 2008;358:2560-72.

\section{Diet therapy}

1. United Kingdom Prospective Diabetes Study (UKPDS) Group. UK Prospective Diabetes Study 7. Response of fasting plasma glucose to diet therapy in newly presenting type II diabetic patients. Metabolism 1990;39:905-12 (level 3).

2. Wing RR, Blair EH, Bononi P, et al. Caloric restriction per se is a significant factor in improvements in glycemic control and insulin sensitivity during weight loss in obese NIDDM patients. Diabetes Care 1994;17:30-36 (level 1).

3. Kulkarni K, Castle G, Gregory R, et al. Nutrition Practice Guidelines for Type 1 Diabetes Mellitus positively affect dietitian practices and patient outcomes. The Diabetes Care and Education Dietetic Practice Group. J Am Diet Assoc 1998;98:62-70/quiz 72-74 (level 3).

4. Anderson JW, Randles KM, Kendall CW, et al. Carbohydrate and fiber recommendations for individuals with diabetes: a quantitative assessment and meta-analysis of the evidence. J Am Coll Nutr 2004;23:5-17 (level 1).

5. Fung TT, van Dam RM, Hankinson SE et al.: Low-carbohydrate diet and all-cause and cause specific mortality: two cohort studies. Ann Intern Med 2010;153: 289-98 (level 2).
6. Garg A. High-monounsaturated-fat diets for patients with diabetes mellitus: a meta-analysis. Am J Clin Nutr 1998;67(Suppl):577S-582S (level 1).

7. Friedberg CE, Janssen MJ, Heine RJ, et al. Fish oil and glycemic control in diabetes: a meta-analysis. Diabetes Care 1998;21:494-500 (level 1).

8. Chandalia M, Garg A, Lutjohann D et al.: Beneficial effects of higher dietary fiber intake in patients with type 2 diabetes mellitus. N Engl J Med 2000;342:1392-1398 (level 1).

9. Imai S, Matsuda M, Hasegawa G, et al. A simple meal plan of "eating vegetables before carbohydrates" was more effective for achieving glycemic control than an exchange-based meal plan in Japanese patients with type 2 diabetes. Asia Pac J Clin Nutr 2011;20:161-8 (level 3).

4 Exercise therapy

1. Boule NG, Kenny GP, Haddad E, et al. Meta-analysis of the effect of structured exercise training on cardiorespiratory fitness in type 2 diabetes mellitus. Diabetologia 2003;46:1071-81 (level 1).

2. Loimaala A, Huikuri HV, Kööbi $\mathrm{T}$, et al. Exercise training improves baroreflex sensitivity in type 2 diabetes. Diabetes 2003;52:1837-42 (level 1).

3. Umpierre D, Ribeiro PA, Kramer CK, et al. Physical activity advice only or structured exercise training and association with HbA1c levels in type 2 diabetes: a systematic review and metaanalysis. JAMA 2011;305:1790-99 (level 1).

4. Boule NG, Haddad E, Kenny GP, et al. Effects of exercise on glycemic control and body mass in type 2 diabetes mellitus: a meta-analysis of controlled clinical trials. JAMA 2001;286:1218-27 (level 1).

5. Balducci S, Zanuso S, Nicolucci A, et al. Effect of an intensive exercise intervention strategy on modifiable cardiovascular risk factors in subjects with type 2 diabetes mellitus: a randomized controlled trial, the Italian Diabetes and Exercise Study (IDES). Arch Intern Med 2010;170:1794-03 (level 1).

6. Dunstan DW, Daly RM, Owen N, et al. High-intensity resistance training improves glycemic control in older patients with type 2 diabetes. Diabetes Care 2002;25:1729-36 (level 1).

7. Castaneda C, Layne JE, Munoz-Orians L, et al. A randomized controlled trial of resistance exercise training to improve glycemic control in older adults with type 2 diabetes. Diabetes Care 2002;25:2335-41 (level 1).

8. Kelley GA, Kelley KS. Effects of aerobic exercise on lipids and lipoproteins in adults with type 2 diabetes: a meta-analysis of randomized-controlled trials. Public Health 2007;121:643-55 (level 1).

9. Ishii T, Yamanaka T, Sato T, et al. Resistance training improves insulin sensitivity in NIDDM subjects without altering maximal oxygen uptake. Diabetes Care 1998;21:1353-55 (level 3).

10. Yamanouchi K, Shinozaki T, Chikada K, et al. Daily waling combined with diet therapy is a useful means for obese NIDDM patients not only to reduce body weight but also to improve insulin sensitivity. Diabetes Care 1995;18:775-778 (level 3).

11. Cuff DJ, Meneilly GS, Martin A, et al. Effective exercise modality to reduce insulin resistance in women with type 2 diabetes. Diabetes Care 2003;26:2977-82 (level 1).

12. Yokoyama H, Emoto M, Araki T, et al. Effect of aerobic exercise on plasma adiponectin levels and insulin resistance in type 2 diabetes. Diabetes Care 2004;27:1756-58 (level 3).

13. Snowling NJ, Hopkins WG. Effects of different modes of exercise training on glucose control and risk factors for complications in type 2 diabetic patients: a meta-analysis. Diabetes Care 2006;29:2518-27 (level 3). 
14. Church TS, Blair SN, Cocreham S, et al. Effects of aerobic and resistance training on hemoglobin A1c levels in patients with type 2 diabetes: a randomized controlled trial. JAMA 2010;304:2253-62 (level 1).

15. Laaksonen DE, Atalay M, Niskanen LK, et al. Aerobic exercise and the lipid profile in type 1 diabetic men: a randomized controlled trial. Med Sci Sports Exerc 2000;32:1541-48 (level $1)$.

5 Treatment with glucose-lowering agents (excluding insulin)

1. United Kingdom Prospective Diabetes Study (UKPDS) Group 13. Relative efficacy of randomly allocated diet, sulphonylurea, insulin, or metformin in patients with newly diagnosed noninsulin-dependent diabetes followed for 3 years. BMJ 1995;310:83-88 (level 1).

2. Stratton IM, Adler AI, Neil HA, et al. Association of glycaemia with macrovascular and microvascular complications of type 2 diabetes (UKPDS 35): prospective observational study. BMJ 2000;321:405-12 (level 2).

3. United Kingdom Prospective Diabetes Study (UKPDS) Group. Intensive blood-glucose control with sulphonylureas or insulin compared with conventional treatment and risk of complications in patients with type 2 diabetes (UKPDS 33). Lancet 1998;352:837-53 (level 1+).

4. United Kingdom Prospective Diabetes Study (UKPDS) Group. Effect of intensive blood-glucose control with metformin on complications in overweight patients with type 2 diabetes (UKPDS 34). Lancet 1998;352:854-65 (level 1+).

5. Selvin E, Bolen S, Yeh HC, et al. Cardiovascular outcomes in trials of oral diabetes medications: a systematic review. Arch Intern Med 2008;168:20270-80 (level 1+).

6. Monami M, Luzzi C, Lamanna C, et al. Three-year mortality in diabetic patients treated with different combinations of insulin secretagogues and metformin. Diabetes Metab Res Rev 2006;22:477-82 (level 2).

7. Holman RR, Cull CA, Turner RC. A randomized double-blind trial of acarbose in type 2 diabetes shows improved glycemic control over 3 years. (UKPDS 44). Diabetes Care 1999;22:960-64 (level 1+).

8. Rosenstock J, Brown A, Fischer J, et al. Efficacy and safety of acarbose in metformin-treated patients with type 2 diabetes. Diabetes Care 1998;21:2050-55 (level 1).

\section{Insulin therapy}

1. The Diabetes Control and Complications Trial (DCCT) Research Group. Early worsening of diabetic retinopathy in the Diabetes Control and Complications Trial. Arch Ophthalmol 1998;116:874-86 (level 1+).

2. United Kingdom Prospective Diabetes Study (UKPDS) Group: United Kingdom Prospective Diabetes Study 24: a 6-year, randomized, controlled trial comparing sulfonylurea, insulin, and metformin therapy in patients with newly diagnosed type 2 diabetes that could not be controlled with diet therapy. Ann Intern Med 1998;128:165-75 (level 1).

3. The Diabetes Control and Complications Trial (DCCT) Research Group. The effect of intensive treatment of diabetes on the development and progression of long-term complications in insulin-dependent diabetes mellitus. $\mathrm{N}$ Engl J Med 1993;329:977-86 (level 1+).

4. The Diabetes Control and Complications Trial (DCCT) Research Group. The effect of intensive diabetes therapy on measures of autonomic nervous system function in the Diabetes Control and Complications Trial (DCCT). Diabetologia 1998;41:416-23 (level 1+).
5. Lawson ML, Gerstein HC, Tsui E, et al. Effect of intensive therapy on early macrovascular disease in young individuals with type 1 diabetes: a systematic review and meta-analysis. Diabetes Care 1999;22(Suppl 2):B35-39 (level 1+).

6. Nathan DM, Cleary PA, Backlund JY, et al. Intensive diabetes treatment and cardiovascular disease in patients with type 1 diabetes. N Engl J Med 2005;353:2643-53. (level 1+).

7. Ohkubo Y, Kishikawa H, Araki E, et al. Intensive insulin therapy prevents the progression of diabetic microvascular complications in Japanese patients with non-insulin-dependent diabetes mellitus: a randomized prospective 6-year study. Diabetes Res Clin Pract 1995;28:103-17 (level 1).

8. United Kingdom Prospective Diabetes Study (UKPDS) Group. Intensive blood-glucose control with sulphonylureas or insulin compared with conventional treatment and risk of complications in patients with type 2 diabetes (UKPDS 33). Lancet 1998;352:837-53 (level 1+).

9. Holman RR, Thorne KI, Farmer AJ, et al. Addition of biphasic, prandial, or basal insulin to oral therapy in type 2 diabetes. N Engl J Med 2007;357:1716-30 (level 1).

10. Liebl A, Prager R, Binz K, et al. Comparison of insulin analogue regimens in people with type 2 diabetes mellitus in the PREFER Study: a randomized controlled trial. Diabetes Obes Metab 2009;11:45-52 (level 2).

11. Feinglos MN, Thacker CR, Lobaugh B, et al. Combination insulin and sulfonylurea therapy in insulin-requiring type 2 diabetes mellitus. Diabetes Res Clin Pract 1998;39:193-9 (level 1).

12. Wright A, Burden AC, Paisey RB, et al. Sulfonylurea inadequacy: efficacy of addition of insulin over 6 years in patients with type 2 diabetes in the U. K. Prospective Diabetes Study (UKPDS 57). Diabetes Care 2002;25:330-6 (level 1).

13. Avilés-Santa L, Sinding J, Raskin P. Effects of metformin in patients with poorly controlled, insulin-treated type 2 diabetes mellitus: a randomized, double-blind, placebo-controlled trial. Ann Intern Med 1999;131:182-8 (level 1).

14. Juntti-Berggren L, Pigon J, Hellström P, et al. Influence of acarbose on post-prandial insulin requirements in patients with type 1 diabetes. Diabetes Nutr Metab 2000;13:7-12 (level 2).

15. Han Y, Kato S, Nemoto M, et al. Usefulness of combination therapy with mixed insulin $\left(50^{\mathrm{R}}\right)$ and an $\alpha$-glucosidase inhibitor in type 2 diabetes. J Jpn Diabetes Soc 2004;47:137-40 (in Japanese) (level 1).

16. Bhat R, Bhansali A, Bhadada S, et al. Effect of pioglitazone therapy in lean type 1 diabetes mellitus. Diabetes Res Clin Pract 2007;78:349-54 (level 1).

17. Raskin P, Rendell M, Riddle MC, et al. A randomized trial of rosiglitazone therapy in patients with inadequately controlled insulin-treated type 2 diabetes. Diabetes Care 2001;24:1226-32 (level 1).

18. Vilsbǿll T, Rosenstock J, Yki-Järvinen H, et al. Efficacy and safety of sitagliptin when added to insulin therapy in patients with type 2 diabetes. Diabetes Obes Metab 2010;12:167-7 (level $1)$.

7 Treatment of diabetic retinopathy

1. Klein R, Klein BE, Moss SE, et al. The Wisconsin Epidemiologic Study of Diabetic Retinopathy: IX. Four-year incidence and progression of diabetic retinopathy when age at diagnosis is less than 30 years. Arch Ophthalmol 1989;107:237-43 (level 2).

2. Klein R, Klein BE, Moss SE, et al. The Wisconsin Epidemiologic Study of Diabetic Nephropathy: X. Four-year incidence and progression of diabetic retinopathy when age at diagnosis is 30 years or more. Arch Ophthalmol 1989;107:237-43 (level 2). 
3. Chew EY. A simplified diabetic retinopathy scale. Ophthalmology 2003;110:1675-76.

4. The Diabetes Control and Complications Trial (DCCT) Research Group. Early worsening of diabetic retinopathy in the Diabetes Control and Complications Trial. Arch Ophthalmol 1998;116:874-86 (level 1+).

5. Ohkubo Y, Kishikawa H, Araki E, et al. Intensive insulin therapy prevents the progression of diabetic microvascular complications in Japanese patients with non-insulin-dependent diabetes mellitus: a randomized prospective 6-year study. Diabetes Res Clin Pract 1995;28:103-17 (level 1).

6. United Kingdom Prospective Diabetes Study (UKPDS) Group. Intensive blood-glucose control with sulphonylureas or insulin compared with conventional treatment and risk of complications in patients with type 2 diabetes (UKPDS 33). Lancet 1998;352:837-53 (level 1+).

7. Matthews DR, Stratton IM, Aldington SJ, et al. Risks of progression of retinopathy and vision loss related to tight blood pressure control in type 2 diabetes mellitus: UKPDS 69. Arch Ophthalmol 2004;122:1631-40 (level 1+).

8. Fong DS, Ferris FL 3rd, Davis MD, et al. Causes of severe vision loss in the Early Treatment Diabetic Retinopathy Study: ETDRS report no. 24. Early Treatment Diabetic Retinopathy Study Research Group. Am J Ophthalmol 1999;127:137-41 (level 1+).

9. The Diabetic Retinopathy Vitrectomy Study Research Group. Early vitrectomy for severe proliferative diabetic retinopathy in eyes with useful vision: results of randomized trial-Diabetic Retinopathy Vitrectomy Study Report 3. Ophthalmology 1988;95:1307-20 (level 1).

10. Diabetic Retinopathy Clinical Research Network. A randomized trial comparing intravitreal triamcinolone acetonide and fo$\mathrm{cal} /$ grid photocoagulation for diabetic macular edema. Ophthalmology 2008;115:1447-49 (level 1).

11. Early Treatment Diabetic Retinopathy Study Research Group. Photocoagulation for diabetic macular edema: Early Treatment Diabetic Retinopathy Study report number 1. Arch Ophthalmol 1985;103:1796-06 (level 1+).

8 Treatment of diabetic nephropathy

1. The Diabetes Control and Complications Trial (DCCT) Research Group. The effect of intensive treatment of diabetes on the development and progression of long-term complications in insulin-dependent diabetes mellitus. $\mathrm{N}$ Engl J Med 1993;329:977-86 (level 1+).

2. Ohkubo Y, Kishikawa H, Araki E, et al. Intensive insulin therapy prevents the progression of diabetic microvascular complications in Japanese patients with non-insulin-dependent diabetes mellitus: a randomized prospective 6-year study. Diabetes Res Clin Pract 1995;28:103-17 (level 1).

3. Ismail-Beigi F, Craven T, Banerji MA, et al. Effect of intensive treatment of hyperglycaemia on microvascular outcomes in type 2 diabetes: an analysis of the ACCORD randomized trial. Lancet 2010;376:419-30 (level 1+).

4. United Kingdom Prospective Diabetes Study (UKPDS) Group. Tight blood pressure control and risk of macrovascular and microvascular complications in type 2 diabetes: UKPDS 38 . BMJ 1998;317:703-13 (level 1+).

5. Shiba $\mathrm{T}$, Inoue $\mathrm{M}$, Tada $\mathrm{H}$, et al. Delapril versus manidipine in hypertensive therapy to halt the type-2-diabetes-melltus-associated nephropathy. Diabetes Res Clin Pract 2000;47:97-104 (level 1).

6. Lewis EJ, Hunsicker LG, Bain RP, et al. The effect of angiotensin-converting-enzyme inhibition on diabetic nephropathy: the Collaborative Study Group. N Engl J Med 1993;329:1456-62 (level 1+).
7. Haneda M, Kikkawa R, Sakai H, et al. Antiproteinuric effect of candesartan cilexetil in Japanese subjects with type 2 diabetes and nephropathy. Diabetes Res Clin Pract 2004;66:87-95 (level 1).

8. Haller H, Ito S, Izzo JL, Jr, et al. Olmesartan for the delay or prevention of microalbuminuria in type 2 diabetes. $\mathrm{N}$ Engl $\mathrm{J}$ Med 2011;364:907-17 (level 1+).

9. Crepaldi G, Carta Q, Deferrari G, et al. Effects of lisinopril and nifedipine on the progression to overt albuminuria in IDDM patients with incipient nephropathy and normal blood pressure: The Italian Microalbuminuria Study Group in IDDM. Diabetes Care 1988;21:104-10 (level 1).

10. Katayama S, Kikkawa R, Isogai S, et al. Effect of captopril or imidapril on the progression of diabetic nephropathy in Japanese with type 1 diabetes mellitus: a randomized controlled study (JAPAN-IDDM). Diabetes Res Clin Pract 2002;55:113-21 (level 1).

11. Makino H, Haneda M, Babazono T, et al. Prevention of transition from incipient to overt nephropathy with telmisartan in patients with type 2 diabetes. Diabetes Care 2007;30:1577-78 (level 1).

12. Sano T, Hotta N, Kawamura T, et al. Effects of long-term enalapril treatment on persistent microalbuminuria in normotensive type 2 diabetic patients: results of a 4-year, prospective, randomized study. Diabet Med 1996;13:120-24 (level 1).

13. Nielsen FS, Rossing P, Gall MA, et al. Long-term effect of lisinopril and atenolol on kidney function in hypertensive NIDDM subjects with diabetic nephropathy. Diabetes 1997;46:1182-88 (level 1).

14. Zeller K, Whittaker E, Sullivan L, et al. Effect of restricting dietary protein on the progression of renal failure in patients with insulin-dependent diabetes mellitus. $\mathrm{N}$ Engl J Med 1991;324:78-84 (level 1).

15. Yokoyama H, Tomonaga O, Hirayama M, et al. Predictors of the progression of diabetic nephropathy and the beneficial effect of antigotensin-converting enzyme inhibitors in NIDDM patients. Diabetologia 1997;40:405-11 (level 2).

16. de Zeeuw D, Remuzzi G, Parving HH, et al. Proteinuria, a target for renoprotection in patients with type 2 diabetic nephropathy: lessons from RENAAL. Kidney Int 2004;65:2309-20 (level 2).

\section{Treatment of diabetic neuropathy}

1. Tesfaye S, Chaturvedi N, Eaton SE, et al. Vascular risk factors and diabetic neuropathy. N Engl J Med 2005;352:341-50 (level 2).

2. Forrest KY, Maser RE, Pambianco G, et al. Hypertension as a risk factor for diabetic neuropathy: a prospective study. Diabetes 1997;46:665-70 (level 2).

3. Adler AI, Boyko EJ, Ahroni JH, et al. Risk factors for diabetic peripheral sensory neuropathy: results of the Seattle Prospective Diabetic Food Study. Diabetes Care 1997;20:1162-67 (level 2).

4. Partanen J, Niskanen L, Lehtinen J, et al. Natural history of peripheral neuropathy in patients with non-insulin-dependent diabetes mellitus. N Engl J Med 1995;333:89-94 (level 2).

5. The Diabetes Control and Complications Trial (DCCT) Research Group. The effect of intensive treatment of diabetes on the development and progression of long-term complications in insulin-dependent diabetes mellitus. $\mathrm{N}$ Engl J Med 1993;329:977-86 (level 1+).

6. United Kingdom Prospective Diabetes Study (UKPDS) Group. Intensive blood-glucose control with sulphonylureas or insulin compared with conventional treatment and risk of complications in patients with type 2 diabetes (UKPDS 33). Lancet 1998;352:837-53 (level 1+).

7. Ohkubo Y, Kishikawa H, Araki E, et al. Intensive insulin therapy prevents the progression of diabetic microvascular 
complications in Japanese patients with non-insulin-dependent diabetes mellitus: a randomized prospective 6-year study. Diabetes Res Clin Pract 1995;28:103-117 (level 1).

8. Max MB, Lynch SA, Muir J, et al. Effects of desipramine, amitriptyline, and fluoxetine on pain in diabetic neuropathy. N Engl J Med 1992;326:1250-56 (level 1).

9. Freeman R, Durso-Decruz E, Emir B. Efficacy, safety, and tolerability of pregabalin treatment for painful diabetic peripheral neuropathy: findings from seven randomized, controlled trials across a range of doses. Diabetes Care 2008;31:1448-54 (level 1).

10. Yasuda H, Hotta N, Nakao K, et al. Superiority of duloxetine to placebo in improving diabetic neuropathic pain: results of a randomized controlled trial in Japan. J Diabetes Invest 2011;2:132-139 (level 1).

\section{Diabetic foot}

1. Armstrong DG, Lvery LA. Negative pressure wound therapy after partial diabetic foot amputation: a multicentre, randomized controlled trial. Lancet 2005;366:1704-10 (level 1).

2. Singh N, Armstrong DG, Lipsky BA. Preventing foot ulcers in patients with diabetes. JAMA 2005;293:217-28 (level 2).

11 Diabetes and periodontitis

1. Nishimura F, Kono T, Fujimoto C, et al. Negative effects of chronic inflammatory periodontal disease on diabetes mellitus. J Int Acad Periodontol 2000;2:49-55 (level 3).

2. Collin HL, Uusitupa M, Miskanen L, et al. Periodontal findings in elderly patients with non-insulin dependent diabetes mellitus. J Periodontol 1998;69:962-66 (level 2).

3. TakahashiK, Nishimura F, Kurihara M, et al. Subgingival microflora and antibody resposes against periodontal bacteria of young Japanese patients with type 1 diabetes mellitus. J Int Acad Periodontol 2001;3:104-11 (level 3).

4. Soskolne WA, Klinger A. The relationship between periodontal disease and diabetes: an overview. Ann Peirodontol 2001;6:91-9 (level 3).

5. Demmer RT, Jacobs DR, Jr., Desvarieux M. Peiodontal disease and incident type 2 diabetes: results from the First National Health and Nutrition Examination Survey and its epidemiologic follow-up study. Diabetes Care 200;31:1373-79 (level 3).

6. Saito T, Shimazaki Y, Kiyohara Y, et al. The severity of periodontal disease is associated with the development of glucose intolerance in non-diabetics: the Hisayama study. J Dent Res 2004;3:445-90 (level 3).

7. Katagiri S, Nitta H, Nagasawa T, et al. Multi-center intervention study on glycohemoglobin (HbA1c) and serum, high-sensitivity CRP (hs-CRP) after local anti-infectious periodontal treatment in type 2 diabetic patients with periodontal disease. Diabetes Res Clin Pract 2009;3:330-15 (level 1).

8. Janket SJ, Wightman A, Baird AE, et al. Does periodontal treatment improve glycemic control in diabetic patients? A meta-analysis of intervention studies. J Dent Res 2005;4:1154-59 (level 1).

9. Teeuw WJ, Gerdes VE, Loos BG. Effect of periodontal treatment on glycemic control of diabetic patients: a systematic review and meta-analysis. Diabetes Care 2010;33:4227 (level 3).

12 Diabetic macroangiopathy

1. Gaede P, Vedel P, Larsen N, et al. Multifactorial intervention and cardiovascular disease in patients with type 2 diabetes. N Engl J Med 2003;348:383-93 (level 1).

2. Griffin SJ, Borch-Johnsen K, Davies MJ et al. Effect of early intensive multifactorial therapy on 5-year cardiovascular outcomes in individuals with type 2 diabetes detected by
screening(ADDITION-Europe):a cluster-randomised trial. Lancet 2011;378:156-67 (level 1+).

3. Iso $\mathrm{H}$, Imano $\mathrm{H}$, Kitamura A, et al. Type 2 diabetes and risk of non-embolic ischaemic stroke in Japanese men and women. Diabetologia 2004;47:2137-44 (level 2).

4. Kimura K, Minematsu K, Kazui S, et al. Mortality and cause of death after hospital discharge in 10,981 patients with ischemic stroke and transient ischemic attack. Cerebrovasc Dis 2005;19:171-78 (level 2).

5. Newman AB, Siscovick DS, Manolio TA, et al. Ankle-arm index as a marker of atherosclerosis in the Cardiovascular Health Study. Caridovascular Heart Study (CHS) Collaborative Research Group. Circulation 1993;88:837-45 (level 3).

6. Sone H, Tanaka S, Tanaka S, et al. Serum level of triglycerides is a potent risk factor comparable to LDL cholesterol for coronary heart disease in Japanese patients with type 2 diabetes: subanaysis of the Japan Diabetes Complications Study (JDCS). J Clin Endocrinol Metab 2011;96:3448-56 (level 2).

7. Yokoyama H, Matsushima M, Kawai K, et al. Low incidence of cardiovascular events in Japanese patients with type 2 diabetes in primary care settings: a prospective study (JDDM20). Diabetes Med 2011;28:1221-28 (level 2).

8. Iso H, Date C, Yamamoto A, et al. Smoking cessation and mortality from cardiovascular disease among Japanese men and women: the JACC Study. Am J Epidemiol 2005;161:170-79 (level 2).

9. Okada S, Hiuge A, Makino H, et al. Effect of exercise intervention on endothelial function and incidence of cardiovascular disease in patients with type 2 diabetes. J Atheroscler Thromb 2010;17:828-33 (level 1).

10. Ray KK, Seshasai SR, Wijesuriya S, et al. Effect of intensive control of glucose on cardiovascular outcomes and death in patients with diabetes mellitus: a meta-analysis of randomised controlled trials. Lancet 2009;373:1765-72 (level 1+).

11. United Kingdom Prospective Diabetes Study (UKPDS) Group: Effect of intensive blood-glucose control with metformin on complications in overweight patients with type 2 diabetes (UKPDS 34). Lancet 1998;352:854-65 (level 1+).

12. Roussel R, Travert F, Pasquet B, et al. Metformin use and mortality among patients with diabetes and atherothrombosis. Arch Intern Med 2010;170:1892-99 (level 2).

13. United Kingdom Prospective Diabetes Study Group. Tight blood pressure control and risk of macrovascular and microvascular complications in type 2 diabetes: UKPDS 38. BMJ 1998;317:703-13 (level 1+).

14. Turnbull F, Neal B, Algert C, et al. Effects of different blood pressure-lowering regimens on major cardiovascular events in individuals with and without diabetes mellitus: results of prospectively designed overviews of randomized trials. Arch Intern Med 2005;165:1410-19 (level 1).

15. Kearney PM, Blackwell L, Collins R, et al. Efficacy of cholesterol-lowering therapy in 18,686 people with diabetes in 14 randomized trials of statins: a meta-analysis. Lancet 2008;371:117-25 (level 1).

16. Gerstein HC, Miller ME, Byington RP, et al. (Action to Control Cardiovascular Risk in Diabetes Study Group). Effects of intensive glucose lowering in type 2 diabetes. $\mathrm{N}$ Engl $\mathrm{J}$ Med 2008;358:2545-59 (level 1+).

17. Bonds DE, Miller ME, Bergental RM, et al. The association between symptomatic, severe hypoglycemia and mortality in type 2 diabetes: retrospective epidemiological analysis of the ACCORD study. BMJ 2010;340:b4909 (level 2).

18. Redon J, Mancia G, Sleight P, et al. Safety and efficacy of low blood pressures among patients with diabetes: subgroup analyses from the ONTARGET (ONgoing Telmisartan Alone and 
in combination with Ramipril Global Endpoint Trial). J Am Coll Cardiol 2012;59:74-83 (level 2).

19. Antithrombotic Trialists' Collaboration. Collaborative metaanalysis of randomized trials of antiplatelet therapy for prevention of death, myocardial infarction, and stroke in high risk patients. BMJ 2002;324:71-86 (level 1).

20. Yasue $\mathrm{H}$, Ogawa $\mathrm{H}$, Tanaka $\mathrm{H}$, et al. Effects of aspirin and trapidil on cardiovascular events after acute myocardial infarction. Japanese Antiplatelets Myocardial Infarction Study (JAMIS) Investigators. Am J Cardiol 1999;83:1308-13 (level 1).

13 Diabetes complicated by obesity

1. Yoshiike N, Nishi N, Matsushima S, et al. Relationship between the severity of obesity based on body mass index and the risk factors for diabetes, hypertension, and hyperglycemia: a multicenter epidemiological study. Obes Res 2000;6:4-17 (in Japanese) (level 3).

2. Yki-Järvinen H, Ryysy L, Kauppila M, et al. Effect of obesity on the response to insulin therapy in non-insulin-dependent diabetes mellitus. J Clin Endocrinol Metab 1997;82:4037-43 (level 1).

3. United Kingdom Prospective Diabetes Study (UKPDS) Group. United Kingdom Prospective Diabetes Study 4: a 6-year, randomized, controlled trial comparing sulfonylurea, insulin, and metformin therapy in patients with newly diagnosed type 2 diabetes that could not be controlled with diet therapy. Ann Intern Med 1998;128:165-75 (level 1+).

14 Hypertension associated with diabetes

1. Gaede P, Lund-Andersen $\mathrm{H}$, Parving $\mathrm{HH}$, et al. Effect of a multifactorial intervention on mortality in type 2 diabetes. N Eng J Med 2008;358:580-91 (level 1).

2. Holman RR, Paul SK, Bethel MA, et al. Long-term follow-up after tight control of blood pressure in type 2 diabetes. N Engl J Med 2008;359:1565-76 (level 2).

3. Hansson L, Zanchetti A, Carruthers SG, et al. Effects of intensive blood-pressure lowering and low-dose aspirin in patients with hypertension: principal results of the Hypertension Optimal Treatment (HOT) randomized trial. HOT Study Group. Lancet 1998;351:1755-62 (level 1+).

4. Cushman WC, Evans GW, Byington RP, et al. Effects of intensive blood-pressure control in type 2 diabetes mellitus. N Engl J Med 2010;362:1575-85 (level 1+).

5. Bangalore S, Kumar S, Lobach I, et al. Blood pressure targets in subjects with type 2 diabetes mellitus/impaired fasting glucose: observations from traditional and bayesina random effects metaanalysis of randomized trials. Circulation 2011;123:2799-810 (level 1+).

6. Heart Outcomes Prevention Evaluation Study Investigators. Effects of ramipril on cardiovascular and microvascular outcomes in people with diabetes mellitus: results of the HOPE study and MICRO-HOPE substudy. Lancet 2000;355:253-59 (level 1+).

7. Haller H, Ito S, Izzo JL, Jr., et al. Olmesartan for the delay or prevention of microalbuminuria in type 2 diabetes. N Engl $\mathrm{J}$ Med 2011;364:907-17 (level 1+).

8. Yusuf S, Teo KK, Pogue J, et al. Telmisartan, ramipril, or both in patients at high risk for vascular events. N Engl J Med 2008;358:1547-59 (level 1+).

9. Katayama S, Kikkawa R, Isogai S, et al. Effect of captopril or imidapril on the progression of diabetic nephropathy in Japanese with type 1 diabetes mellitus: a randomized controlled study (JAPAN-IDDM). Diabetes Res Clin Pract 2002;55:113-21 (level 1).

10. Ogihara T, Nakao K, Fukui T, et al. Effects of candesartan compared with amlodipine in hypertensive patients with high cardiovascular risk: candesartan antihypertensive survival evaluation in Japan trial. Hypertension 2008;51:393-98 (level 1+).

11. Katayama S, Kawamori R, Iwamoto Y, et al. In half of hypertensive diabetics, co-administration of a calcium channel blocker and an angiotensin-converting enzyme inhibitor achieved a target blood pressure of $<130 / 80 \mathrm{mmHg}$ : the azelnipidine and temocapril in hypertensive patients with type 2 diabetes (ATTEST) study. Hypertens Res 2008;31:1499-08 (level 1).

12. Jamerson K, Weber MA, Bakris GL, et al. Benazeprial plus amlodipine or hydrochlorothiazide for hypertension in high-risk patients. N Enl J Med 2008;359:2417-28 (level 1+).

13. Tuomilehto J, Rastenyte D, Birkenhäger $\mathrm{WH}$, et al. Effects of calcium-channel blockade in older patients with diabetes and systolic hypertension: Systolic Hypertension in Europe Trial Investigators. N Engl J Med 1999;340:677-84 (level 1).

15 Dyslipidemia associated with diabetes

1. Collins R, Armitage J, Parish S, et al. (Heart Protection Study Collaborative Group). MRC/BHF Heart Protection Study of cholesterol-lowering with simvastatin in 5963 people with diabetes: a randomized placebo-controlled trial. Lancet 2003;361:2005-16 (level 1+).

2. Sone H, Katagiri A, Ishibashi $\mathrm{S}$, et al. Effects of lifestyle modifications on patients with type 2 diabetes: the Japan Diabetes Complications Study (JDCS) study design, baseline analysis and 3 year-interim report. Horm Metab Res 2002;34:509-15 (level 2).

3. Sone $\mathrm{H}$, Ito $\mathrm{H}$, Ohashi $\mathrm{Y}$, et al. Obesity and type 2 diabetes in Japanese patients. Lancet 2003;361:85 (level 2).

4. Kearney PM, Blackwell L, Collins R, et al. Efficacy of cholesterol-lowering therapy in 18,686 people with diabetes in 14 randomized trials of statins: a meta-analysis. Lancet 2008;371:117-25 (level 1+).

5. Japan Atherosclerosis Society(JAS) Guidelines for Prevention of Atherosclerotic Cardiovascular Diseases 2012 (in Japanese).

6. Tajima N, Kurata H, Nakaya N, et al. Pravastatin reduces the risk for cardiovascular disease in Japanese hypercholesterolemic patients with impaired fasting glucose or diabetes: diabetes subanalysis of the Management of Elevated Cholesterol in the Primary Prevention Group of Adult Japanese (MEGA) Study. Atherosclerosis 2008;199:455-62 (level 2).

7. Keech A, Simes RJ, Barter P, et al. Effects of long-term fenofibrate therapy on cardiovascular events in 9785 people with type 2 diabetes mellitus (the FIELD study): randomized controlled trial. Lancet 2005;366:1849-61 (level 1+).

8. Yokoyama M, Origasa $H$, Matsuzaki $M$, et al. Effects of eicosapentaenoic acid on major coronary events in hypercholesterolaemic patients (JELIS): a randomized open-label, blinded endpoint analysis. Lancet 2007;369;1090-98 (level 1+).

16 Impaired glucose metabolism in pregnant women

1. Hanson U, Persson B, Thunell S. Relationship between haemoglobin A1C in early type 1 (insulin-dependent) diabetic pregnancy and the occurrence of spontaneous abortion an fetal malformation in Sweden. Diabetologia 1990;33:100-04 (level 3).

2. Ray JG, O'Brien TE, Chan WS. Preconception care and the risk of congenital anomalies in the offspring of women with diabetes mellitus: a meta-analysis. QJM 2001;94:435-44 (level 1+).

3. Gordon M, Landon MB, Samuels P, et al. Perinatal outcome and long-term follow-up associated with modern management of diabetic nephropathy. Obstet Gynecol 1996;87:401-09 (level 2).

4. Klein BE, Moss SE, Klein R. Effect of pregnancy on progression of diabetic retinopathy. Diabetes Care 1990;13:34-40 (level 2). 
5. Chew EY, Mills JL, Metzer BE, et al. Metabolic control and progression of retinopathy: the Diabetes in Early Pregnancy Study. National Institute of Child Health and Human Development Diabetes in Early Pregnancy Study. Diabetes Care 1995; 18:631-37 (level 3).

6. Ekbom P, Damm P, Feldt-Rasmussen B, et al. Pregnancy outcome in type 1 diabetic women with microalbuminuria. Diabetes Care 2001;24:1739-44 (level 2).

7. Purdy LP, Hantsch CE, Molitch ME, et al. Effect of pregnancy on renal function in patients with moderate-to-severe diabetic renal insufficiency. Diabetes Care 1996;19:1067-74 (level 3).

8. Griffin ME, Coffey M, Johnson H, et al. Universal vs. risk factor-based screening for gestational diabetes mellitus: detection rates, gestation at diagnosis and outcome. Diabet Med 2000;17:26-32 (level 1).

9. de Veciana M, Major CA, Morgan MA, et al. Postprandial versus preprandial blood glucose monitoring in women with gestational diabetes mellitus requiring insulin therapy. $\mathrm{N}$ Engl $\mathrm{J}$ Med 1995;333:1237-41 (level 2).

10. Landon MB, Spong CY, Thom E, et al. A multicenter, randomized trial of treatment for mild gestational diabetes. N Engl J Med 2009;361:1339-48 (level 1).

11. Hellmuth E, Damm P, Molsted-Pedersen L. Oral hypoglycemic agents in 118 diabetic pregnancies. Diabet Med 2000;17:507-11 (level 2).

12. Mukhopadhyay A, Farrell T, Fraser RB, et al. Continuous subcutaneous insulin infusion vs intensive conventional insulin therapy in pregnant diabetic women: a systematic review and metaanalysis of randomized, controlled trials. Am J Obstet Gynecol 2007;197:447-56 (level 2).

13. Mathiesen ER, Kinsley B, Amiel SA, et al. Maternal glycemic control and hypoglycemia in type 1 diabetic pregnancy: a randomized tiral of insulin aspart versus human insulin in 322 pregnant women. Diabetes Care 2007;30:771-6 (level 2).

14. Mathiesen ER, Hod M, Ivanisevic M, et al. (Detemir in Pregnancy Study Group). Maternal efficacy and safety outcomes in a randomized, controlled trial comparing insulin detemir with NPH insulin in 310 pregnant women with type 1 diabetes. Diabetes Care 2012;35:2012-17 (level 1+).

15. Bellamy L, Casas JP, Hingorani AD, et al. Type 2 diabetes mellitus after gestational diabetes: a systematic review and meta-analysis. Lancet 2009;373:1773-79 (level 1+).

17 Pediatric/adolescent diabetes

1. White NH, Cleary PA, Dahms W, et al. (Diabetes Control and Complications Trial [DCCT]/Epidemiology of Diabetes Interventions and Complications [EDIC] Research Group). Beneficial effects of intensive therapy of diabetes during adolescence: outcomes after the conclusion of the Diabetes Control and Complications Trial (DCCT). J Pediatr 2001;139:804-12 (level 2).

2. Minami M, Otani T, Yokoyama H, et al. Changes over time in insulin dose and development/growth status in insulin-dependent diabetic patients more than 25 years after disease onset at less than 8 years old. Diabetes 1993;36:455-60 (in Japanese) (level 2).

3. Hershey T, Perantie DC, Warren SL, et al. Frequency and timing of severe hypoglycemia affects spatial memory in children with type 1 diabetes. Diabetes Care 2005;28:2372-77 (level 3).

4. Musen G, Jacobson AM, Ryan CM, et al. Impact of diabetes and its treatment on cognitive function among adolescents who participated in the Diabetes Control and Complications Trial. Diabetes Care 2008;31:1933-38 (level 2).

5. Yokoyama H, Okudaira M, Otani T, et al. Existence of earlyonset NIDDM Japanese demonstrating severe diabetic complications. Diabetes Care 1997;20:844-47 (level 2).
18 Diabetes (and bone metabolism) in the elderly

1. Harris MI, Flegal KM, Cowie CC, et al. Prevalence of diabetes, impaired fasting glucose, and impaired glucose tolerance in U. S. adults: the Third National Health and Nutrition Examination Survey, 1988-1994. Diabetes Care 1998;21:518-24 (level 4).

2. Araki A, Ito H, Hattori A, et al. Risk factors for development of retinopathy in elderly Japanese patients with diabetes mellitus. Diabetes Care 1993;16:1184-86 (level 3).

3. Bethel MA, Sloan FA, Belsky D, et al. Longitudinal incidence and prevalence of adverse outcomes of diabetes mellitus in elderly patients. Arch Intern Med 2007;167:921-27 (level 2).

4. Cukierman T, Gerstein HC, Williamson JD. Cognitive decline and dementia in diabetes-systematic overview of prospective observational studies. Diabetologia 2005;48:2460-69 (level 2).

5. Bruce DG, Casey G, David WA, et al. Vascular depression in older people with diabetes. Diabetologia 2006;49:2828-36 (level 4).

6. Gregg EW, Mangione CM, Cauley JA, et al. Diabetes and incidence of functional disability in older women. Diabetes Care 2002;25:61-67 (level 2).

7. Janghorbani M, Van Dam RM, Willett WC, et al. Systematic review of type 1 and type 2 diabetes mellitus and risk of fracture. Am J Epidemiol 2007;166:495-05 (level 2).

8. Wahl PW, Savage PJ, Psaty BM, et al. Diabetes in older adults: comparison of 1997 American Diabetes Association classification of diabetes mellitus with 1985 WHO classification. Lancet 1998;352:1012-15 (level 4).

9. Miller CK, Edwards L, Kissling G, et al. Nutrition education improves metabolic outcomes among older adults with diabetes mellitus: results from a randomized controlled trial. Prev Med 2002;34:252-9 (level 1).

10. Wannamethee SG, Shaper AG, Walker M. Changes in physical activity, mortality, and incidence of coronary heart disease in older men. Lancet 1998;351:1603-08 (level 2).

11. Ellekjaer H, Holmen J, Ellekjaer E, et al. Physical activity and stroke mortality in women: 10-year follow-up of the NordTrondelag health survey, 1984-1986. Stroke 2000;31:14-18 (level 2).

12. Braun AK Kubiak T, Kuntsche J, et al. SGS: a structured treatment and teaching programme for older patients with diabetes mellitus-a prospective randomized controlled multicentre trial. Age Ageing 2009;38:390-6 (level 1).

13. Johnson PS, Lebovitz HE, Coniff RF, et al. Advantages of alpha-glucosidase inhibition as monotherapy in elderly type 2 diabetic patients. J Clin Endocrinol Metab 1998;83:1515-22 (level 1).

14. Gregorio F, Ambrosi F, Manfrini S, et al. Poorly controlled elderly type 2 diabetic patients: the effects of increasing sulphonylurea dosages or adding metformin. Diabet Med 1999;16:1016-24 (level 1).

15. Seltzer HS. Drug-induced hypoglycemia: a review of 1418 cases. Endocrinol Metab Clin North Am 1989;18:163-83 (level 4).

16. Lee SJ, Boscardin WJ, Stijacic Cenzer I, et al. The risks and benefits of implementing glycemic control guidelines in frail older adults with diabetes mellitus. J Am Geriatr Soc 2011;59:666-72 (level 2).

17. Whitmer RA, Karter Aj, Yaffe K, et al. Hypoglycemic episodes and risk of dementia in older patients with type 2 diabetes mellitus. JAMA 2009;301:1565-72 (level 2).

18. Calabrese AT, Coley KC, DaPos SV, et al. Evaluation of prescribing practices: risk of lactic acidosis with metformin therapy. Arch Intern Med 2002;162:434-37 (level 4). 
19. Huang ES, Liu JY, Moffet HH, et al. Glycemic control, complications, and death in older diabetic patients: the diabetes and aging society. Diabetes Care 2011;34:1329-36 (level 3).

20. Sosa M, Saavedra P, Jodar E, et al. Bone mineral density and risk of fractures in aging, obese post-menopausal women with type 2 diabetes: the GUIMO Study. Aging Clin Exp Res 2009;21:27-32 (level 2).

21. Loke YK, Singh S, Furberg CD. Long-term use of thiazolidinediones and fractures in type 2 diabetes: a meta-analysis. CMAJ 2009;180:32-39 (level 2).

22. Keegan TH, Schwartz AV, Bauer DC, et al. Effect of alendronate on bone mineral density and biochemical markers of bone turnover in type 2 diabetic women: the fracture intervention trial. Diabetes Care 2004;27:1547-53 (level 1).

19 Acute metabolic complications of diabetes

1. Kitabchi AE, Umpierrez GE, Miles JM, et al. Hyperglycemic crises in adults patients with diabetes. Diabetes Care 2009;32:1335-43.

2. Gamba G, Oseguera J, Castrejon M, et al. Bicarbonate therapy in severe diabetic ketoacidosis: a double blind, randomized, placebo controlled trial. Rev Invest Clin 1991;43:234-38 (level 1).

3. Seidowsky A, Nseir S, Houdret $\mathrm{N}$ et al.: Metformin-associated lactic acidosis: a prognostic and therapeutic study. Crit Care Med 2009;37: 2191-96 (level 4).

4. Rosenstock J, Dailey G, Massi-Benedetti M, et al. Reduced hypoglycemia risk with insulin glargine: a meta-analysis comparing insulin glargine with human NPH insulin in type 2 diabetes. Diabetes Care 2005;28:950-55 (level 1).

5. Hemmingsen B, Lund SS, Gluud C, et al. Intensive glycaemic control for patients with type 2 diabetes: systematic review with meta-analysis and trial sequential analysis of randomized clinical trials. BMJ 2011;343:d6898 (level 1+).

20 Diabetes, infectious diseases and sick days

1. Hotta N, Nakamura J, Iwamoto $Y$, et al. Cause of death in Japanese diabetics based on the results of a survey of 18,385 diabetics during 1991-2000. Report of Committee on Cause of Death in Diabetes Mellitus. J Jpn Diab Soc 2007;50:47-61 (in Japanese) (level 4).

21 Diabetes and pancreas/islet transplantation

1. Gruessner AC. 2011 update on pancreas transplantation: comprehensive trend analysis of 25,000 cased followed up over the course of 24 years at the International Pancreas Transplant Registry (IPTR). Rev Diabet Stud 2011;8:6-16 (level 3).

2. Ito T, Ishibashi M, Japan Pancreas/Islet Transplantation Study Group Pancreatic Transplantation Division. Report of the Japanese Pancreas Transplant Registry (2011). Transplantation 2011;46:546-51 (in Japanese) (level 3).

3. Weiss AS, Smits G, Wiseman AC. Twelve-month pancreas graft function significantly influences surveil following simultaneous pancreas-kidney transplantation. Clin J Am Soc Nephrol 2009;4:988-95 (level 3).

4. Browne S, Gill J, Dong J, et al. The impact of pancreas transplantation on kidney allograft survival. Am $\mathrm{J}$ Transplant 2011;11:1951-58 (level 3).

5. Sureshkumar KK, Patel BM, Markatos A, et al. Quality of life after organ transplantation in type 1 diabetics with end-stage renal disease. Clin Transplant 2006;20:19-25 (level 2).

6. Biesenbach G, Konigsrainer A, Gross C, et al. Progression of macrovascular diseases is reduced in type 1 diabetic patients after more than 5 years successful combined pancreas-kidney transplantation in comparison to kidney transplantation alone. Transpl Int 2005;18:1054-60 (level 2).

7. Ryan EA, Paty BW, Senior PA, et al. Five-year follow-up after clinical islet transplantation. Diabetes 2005;54:2060-69 (level 2).

8. Fiorina P, Shapiro AM, Ricordi C, et al. The clinical impact of islet transplantation. Am J Transplant 2008;8:1990-97 (level 3).

9. Dong M, Parsaik AK, Erwin PJ, et al. Systematic review and meta-analysis: islet autotransplantation after pancreatectomy for minimizing diabetes. Clin Endocrinol 2011;75:771-9 (level 4).

22 Education for diabetes self-management

1. The Diabetes Control and Complications Trial (DCCT) Research Group. The effect of intensive treatment of diabetes on the development and progression of long-term complications in insulin-dependent diabetes. N Engl J Med 1993;329:977-86 (level 1+).

2. Knowler WC, Barrett-Connor E, Fowler SE, et al. (Diabetes Prevention Program Research Group). Reduction in the incidence of type 2 diabetes with lifestyle intervention or metformin. N Engl J Med 2002;346:393-02 (level 1+).

3. Minet L, Moller S, Vach W, et al. Mediating the effect of selfcare management intervention in type 2 diabetes: a meta-analysis of 47 randomized controlled trials. Patient Educ Couns 2010;80:29-41 (level 1).

4. Shojania KG, Ranji SR, McDonald KM, et al. Effects of quality improvement strategies for type 2 diabetes on glycemic control: a meta-regression analysis. JAMA 2006;296:427-40 (level 2).

5. Tshiananga JK, Kocher S, Weber C, et al. The effect of nurseled diabetes self-management education on glycosylated hemoglobin and cardiovascular risk factors: a meta-analysis. Diabetes Educ 2012;38:108-23 (level 1).

6. Ohkubo Y, Kishikawa H, Araki E, et al. Intensive insulin therapy prevents the progression of diabetic microvascular complications in Japanese patients with non-insulin-dependent diabetes mellitus: a randomized prospective 6-year study. Diabetes Res Clin Pract 1995;28:103-17 (level 1) and (level 2).

7. de Veciana M, Major CA, Morgan MA, et al. Postprandial versus preprandial blood glucose monitoring in women with gestational diabetes mellitus requiring insulin therapy. N Engl J Med 1995;333:1237-41 (level 1).

8. Schachinger $\mathrm{H}$, Hegar K, Hermanns $\mathrm{N}$, et al. Randomized controlled clinical trial of Blood Glucose Awareness Training (BGAT III) in Switzerland and Germany. J Behav Med 2005;28:587-94 (level 1).

9. Malanda UL, Welschen LM, Riphagen II, et al. Self-monitoring of blood glucose in patients with type 2 diabetes mellitus who are not using insulin. Cochrane Database Syst Rev 2012;1:CD005060. (level 1).

10. Rachmani R, Levi Z, Slavachevski I, et al. Teaching patients to monitor their risk factors retards the progression of vascular complications in high-risk patients with type 2 diabetes mellitus-a randomized prospective study. Diabet Med 2002;19:385-92 (level 1).

11. Ismail K, Winkley K, RAbe-Hesketh S. Systematic review and meta-analysis of randomized controlled trials of psychological interventions to improve glycaemic control in patients with type 2 diabetes. Lancet 2004;363:1589-97 (level 1).

12. Winkley K, Ismail K, Landau S, et al. Psychological interventions to improve glycaemic control in patients with type 1 diabetes: systematic review and meta-analysis of randomized controlled trials. BMJ 2006;333:65 (level 1).

13. Phillips LS, Ziemer DC, Doyle JP, et al. An endocrinologistsupported intervention aimed at providers improves diabetes management in a primary care site: improving primary care of 
African Americans with diabetes (IPCAAD) 7. Diabetes Care 2005;28:2352-60 (level 1+).

23 Prevention of type 2 diabetes

1. American Diabetes Association: Standards of medical care in diabetes-2010. Diabetes Care 2010;33(Suppl 1):S11-61.

2. Heianza Y, Hara S, Arase Y, et al. HbA1c 5.7-6.4 \% and impaired fasting glucose for diagnosis of prediabetes and risk of progression to diabetes in Japan (TOPICS 3): a longitudinal cohort study. Lancet 2011;378:147-55 (level 2).

3. de Munter JS, Hu FB, Spiegelman D, et al. Whole grain, bran, and germ intake and risk of type 2 diabetes: a prospective cohort study and systematic review. PLoS Med 2007;4:e261 (level 2).

4. Dong JY, Zhang L, Zhang YH, et al. Dietary glycaemic index and glycaemic load in relation to the risk of type 2 diabetes: a meta-analysis of prospective cohort studies. $\mathrm{Br} \mathrm{J}$ Nutr 2011;106:1649-54 (level 2).

5. Carter P, Gray LJ, Troughton J, et al. Fruit and vegetable intake and incidence of type 2 diabetes mellitus: systematic review and meta-analysis. BMJ 2010;341:c4229 (level 2).

6. Nanri A, Mizoue T, Noda M, et al. Fish intake and type 2 diabetes in Japanese men and women: the Japan Public Health Center-based Prospective Study. Am J Clin Nutr 2011;94:884-91 (level 2).

7. Kosaka K, Noda M, Kuzuya T. Prevention of type 2 diabetes by lifestyle intervention: a Japanese trial in IGT males. Diabetes Res Clin Pract 2005;67:152-62 (level 1).

8. Saito T, Watanabe M, Nishida J, et al. Lifestyle modification and prevention of type 2 diabetes in overweight Japanese with impaired fasting glucose levels: a randomized controlled trial. Arch Intern Med 2011;171:1352-60 (level 1).

9. Jeon CY, Lokken RP, Hu FB, et al. Physical activity of moderate intensity and risk of type 2 diabetes: a systematic review. Diabetes Care 2007;30:744-52 (level 2).

10. Willi C, Bodenmann P, Ghali WA, et al. Active smoking and the risk of type 2 diabetes: a systematic review and meta-analysis. JAMA 2007;298:2654-64 (level 2).

11. Koppes LL, Dekker JM, Hendriks HF, et al. Moderate alcohol consumption lowers the risk of type 2 diabetes: a meta-analysis of prospective observational studies. Diabetes Care 2005;28:719-25 (level 2).

12. Waki K, Noda M, Sasaki S, et al. Alcohol consumption and other risk factors for self-reported diabetes among middle-aged Japanese: a population-based prospective study in the JPHC study cohort I. Diabet Med 2005;22:323-31 (level 2).

13. Kato M, Noda M, Inoue M, et al. Psychological factors, coffee and risk of diabetes mellitus among middle-aged Japanese: a population-based prospective study in the JPHS study cohort. Endocr J 2009;56:459-68 (level 2).
14. Cappuccio FP, D’Elia L, Strazzullo P, et al. Quantity and quality of sleep and incidence of type 2 diabetes: a systematic review and meta-analysis. Diabetes Care 2010;33:414-20 (level 2).

15. Mezuk B, Eaton WW, Albrecht S, et al. Depression and type 2 diabetes over the lifespan: a meta-analysis. Diabetes Care 2008;31:2383-90 (level 2).

16. Knowler WC, Barrett-Connor E, Fowler SE, et al. (Diabetes Prevention Program Research Group). Reduction in the incidence of type 2 diabetes with lifestyle intervention or metformin. N Engl J Med 2002;346:393-03 (level 1+).

17. Gillies CL, Abrams KR, Lambert PC, et al. Pharmacological and lifestyle interventions to prevent or delay type 2 diabetes in people with impaired glucose tolerance: systematic review and meta-analysis. BMJ 2007;334:299 (level 1).

18. Kawamori R, Tajima Iwamoto Y, et al. Voglibose for prevention of type 2 diabetes mellitus: a randomized, double-blind trial in Japanese individuals with impaired glucose tolerance. Lancet 2009;373:1607-14 (level 1+).

19. Chiasson JL, Josse RG, Gomis R. Acarbose for prevention of type 2 diabetes mellitus: the STOP-NIDDM randomized trial. Lancet 2002;359:2072-77 (level 1+).

24 Metabolic syndrome

1. Committee on Diagnostic Criteria for Metabolic Syndrome. Metabolic Syndrome: Its Definition and Diagnostic Criteria. J Jpn Soc Intern 2005;94:794-09 (in Japanese).

2. Doi Y, Ninomiya T, Hara J, et al. Proposed criteria for metabolic syndrome in Japanese based on prospective evidence: the Hisayama study. Stroke 2009;40:1187-94 (level 2).

3. Irie $\mathrm{F}$, Iso $\mathrm{H}$, Noda $\mathrm{H}$, et al. Associations between metabolic syndrome and mortality from cardiovascular disease in Japanese general population, findings on overweight and non-overweight individuals: Ibaraki Prefectural Health Study. Cir J 2009;73:1635-42 (in Japanese) (level 2).

4. Hiuge-Shimizu A, Kishida K, Funahashi T, et al. Absolute value of visceral fat area measured on computed tomography scans and obesity-related cardiovascular risk factors in large-scale Japanese general population (the VACAION-J-study). Ann Med 2012;44:82-92 (level 4).

5. Sone $\mathrm{H}$, Tanaka $\mathrm{S}$, Iimuro $\mathrm{S}$, et al. Components of metabolic syndrome and their combinations as predictors of cardiovascular disease in Japanese patients with type 2 diabetes. Implications for improved definition. Analysis from Japan Diabetes Complications Study (JDCS). J Atheroscler Thromb 2009;16:380-87 (level 4).

6. Ilanne-Parikka P, Eriksson JG, Lindstrom J, et al. Effect of lifestyle intervention on the occurrence of metabolic syndrome and its components in the Finnish Diabetes Prevention Study. Diabetes Care 2008;31:805-07 (level 2). 